\title{
The transcriptional activator PAX3-FKHR rescues the defects of Pax3 mutant mice but induces a myogenic gain-of-function phenotype with ligand-independent activation of Met signaling in vivo
}

\author{
Frédéric Relaix, ${ }_{1}^{1}$ Mariarosa Polimeni, ${ }^{2}$ Didier Rocancourt, ${ }^{1}$ Carola Ponzetto, ${ }^{3}$ Beat W. Schäfer, ${ }^{4}$ and \\ Margaret Buckingham ${ }^{1,5}$ \\ ${ }^{1}$ CNRS URA 2375, Department of Developmental Biology, Pasteur Institute, 75724 Paris Cedex 15, France; ${ }^{2}$ Department of \\ Experimental Medicine, Section of Anatomy, University of Pavia, 27100 Pavia, Italy; ${ }^{3}$ Department of Anatomy, \\ Pharmacology and Forensic Medicine, University of Turin, 10126 Turin, Italy; ${ }^{4}$ Division of Clinical Chemistry and \\ Biochemistry, Department of Pediatrics, University of Zurich, CH-8032 Zurich, Switzerland
}

Pax3 is a key transcription factor implicated in development and human disease. To dissect the role of Pax3 in myogenesis and establish whether it is a repressor or activator, we generated loss- and gain-of-function alleles by targeting an $n L a c Z$ reporter and a sequence encoding the oncogenic fusion protein PAX3-FKHR into the Pax3 locus. Rescue of the Pax3 mutant phenotypes by PAX3-FKHR suggests that Pax3 acts as a transcriptional activator during embryogenesis. This is confirmed by a Pax reporter mouse. However, mice expressing PAX3-FKHR display developmental defects, including ectopic delamination and inappropriate migration of muscle precursor cells. These events result from overexpression of c-met, leading to constitutive activation of Met signaling, despite the absence of the ligand SF/HGF. Haploinsufficiency of c-met rescues this phenotype, confirming the direct genetic link with Pax3. The gain-of-function phenotype is also characterized by overactivation of MyoD. The consequences of PAX3-FKHR myogenic activity in the limbs and cervical and thoracic regions point to differential regulation of muscle growth and patterning. This gain-of-function allele provides a new approach to the molecular and cellular analysis of the role of Pax3 and of its target genes in vivo.

[Keywords: Pax3; Met; myogenesis; migration; mouse; embryo; rhabdomyosarcoma]

Received July 30, 2003; revised version accepted October 22, 2003.

Transcription factors of the Pax family play an important role during development, and spontaneously occurring mutations affecting $P A X$ genes in humans, as in mice, lead to major abnormalities in the formation of organs and tissues (Tremblay and Gruss 1994). Pax6, for example, is a key factor in eye development (van Heyningen and Williamson 2002), whereas Pax5 determines the emergence of the B lymphocyte cell lineage from hematopoietic precursors (Nutt et al. 2001). Pax genes are also important for the formation of the vertebral column, ribs, and skeletal muscles, which derive from somites, segments of paraxial mesoderm located on either side of

${ }^{5}$ Corresponding author.

E-MAIL margab@pasteur.fr; FAX 33-1-40-61-34-52.

Article and publication are at http://www.genesdev.org/cgi/doi/10.1101/ gad.281203. the neural tube in the embryo (Tajbakhsh and Buckingham 2000). In the ventral part of the somite, the sclerotome, $P a x 1$ and $P a x 9$ are implicated in the formation of bone and cartilage, whereas dorsally, in the dermomyotome, Pax3 and its ortholog Pax7 are expressed.

Pax3 is a key regulator of myogenesis. In splotch $(S p)$ mice (Auerbach 1954), which have undergone spontaneous mutations in the Pax3 locus, myogenic progenitor cells fail to delaminate from the epithelium of the dermomyotome and migrate away from the somite to other sites of skeletal muscle formation. As a consequence, muscle cells are absent from the limbs, and the hypoglossal cord fails to form, resulting in the absence of pharyngeal and tongue muscles. The diaphragm muscle is also compromised in splotch mice, as are some other body muscles formed from the hypaxial (as distinct from epaxial-adjacent to the axis) part of the dermomyotome 
(Franz et al. 1993; Bober et al. 1994; Goulding et al. 1994; Tremblay et al. 1998). In contrast, epaxial muscles, together with those hypaxial muscles that also form in situ without extensive cell migration, are less affected. Notably, the myotome, which is the first skeletal muscle mass to form in the central compartment of the somite, is present, although it is reduced hypaxially (see Tajbakhsh and Buckingham 2000). It is thought that part at least of the splotch phenotype is caused by the absence of Met, a tyrosine kinase receptor expressed in the hypaxial dermomyotome and in migrating muscle cells; in c-met mutant mice, muscle progenitor cells fail to migrate from the somite, and limb muscles, for example, are absent (Bladt et al. 1995).

A second facet of the role of Pax3 in skeletal myogenesis was revealed by crossing splotch mice with mice in which an allele of $M y f 5$ had been inactivated by targeting with an nlac $Z$ reporter. Myf5 is a member of the basic helix-loop-helix family of myogenic regulatory factors and is the first to be expressed in the mouse embryo. In the absence of Myf5 and MyoD, also a member of this family, skeletal muscle does not form, and myogenic precursor cells are absent (Rudnicki et al. 1993). In $\mathrm{Pax3}^{-/-} / \mathrm{Myf5}^{-/-}$double mutants, $\mathrm{MyoD}$ is not activated and all skeletal muscles are lacking from the trunk, as well as the limbs (Tajbakhsh et al. 1997). This, therefore, demonstrates that Pax3 and Myf5 act genetically upstream of $M y o D$ as myogenic determination genes.

Although Pax3 plays an important role in myogenesis, its mode of action as a transcription factor and its direct targets in vivo are poorly understood. As a member of the Pax family, it has a characteristic paired domain DNAbinding motif and, like some other Pax proteins, a homeodomain and a conserved octapeptide motif (Czerny et al. 1993; Tremblay and Gruss 1994). It is a poor transcriptional activator (Bennicelli et al. 1999) and, indeed, Pax3 co-factors, such as HIRA (named for its sequence similarity to two yeast proteins, Hirlp and Hir2p), isolated from cultured cells (Magnaghi et al. 1998), or Daxx (Hollenbach et al. 1999) act as transcriptional corepressors. It is not clear how Pax3 influences $M y o D$ transcription; this may take place via a conserved genetic cascade involving Six genes (Relaix and Buckingham 1999). c-met has been regarded as a Pax3 target because of transactivation on its promoter in vitro (Epstein et al. 1996) and because c-met transcripts are not detectable in splotch mutants (Yang et al. 1996), although this conclusion is compromised by the fact that the cells that would normally express c-met are lost (Borycki et al. 1999).

Pax3 is not only present in skeletal muscle progenitor cells. It is also expressed in regions of the brain, in the dorsal neural tube, and in neural crest cells that migrate from it (Dahl et al. 1997). Splotch embryos show exencephaly and spina bifida caused by a failure of neural tube closure, as well as defects in neural crest derivatives caused by a lack of neural crest migration. Again there is apoptosis in the dorsal neural tube in the absence of Pax3 (Borycki et al. 1999). In this situation, too, the action of Pax3 as a transcription factor is poorly understood. There are several potential target genes, such as Mitf (Microph- thalmia-associated transcription factor) or TRP-1 (tyrosinase-related protein-1) expressed in melanocytes (neural crest derivative; Watanabe et al. 1998; Galibert et al. 1999|, although again the evidence comes from in vitro studies.

In addition to its role in normal development, Pax3 is associated with the formation of tumors. PAX3-FKHR arises in humans as a result of a chromosomal translocation, $\mathrm{t}(2 ; 13)$, which leads to the fusion of the potent C-terminal transcription activation domain of FKHR (FOX01A) to the N-terminal region of PAX3, which includes the intact paired-box and homeobox DNA-binding elements. This chromosomal translocation, together with a translocation $\mathrm{t}(1 ; 13)$, which generates PAX7$F K H R$, are associated with alveolar rhabdomyosarcomas (ARMS), a highly malignant class of pediatric soft tissue tumors, with skeletal muscle characteristics (Barr 2001). $P A X 3-F K H R$ is a potent gain-of-function mutation (Bennicelli et al. 1999), and is thought to exert its role in alveolar rhabdomyosarcomas through aberrant regulation of PAX3 target genes. Previous mouse models of ARMS, based on PAX3-FKHR transgenes (Anderson et al. 2001) or targeted mutations (Lagutina et al. 2002), gave phenotypes principally resulting from neural crest perturbations, but were not informative in the context of Pax3 function during the onset of myogenesis.

To examine Pax3 activity in vivo, we have created a gain-of-function mutation in $P a x 3$, by targeting the gene with a $P A X 3-F K H R$ fusion sequence. This inclusion of an nlacZ reporter gene makes it possible to follow the cells that express this allele. Analysis of the phenotypes of these embryos, compared with that of Pax $3^{\text {IRESnLacZ/+ }}$ controls, gives new insights into the role of Pax3 in the embryo and demonstrates that it acts in vivo as a transcriptional activator of c-met and MyoD. These experiments also reveal ligand-independent Met activation, with mechanistic implications for PAX3-FKHR function in rhabdomyosarcoma.

\section{Results}

Generation of loss- and gain-of-function alleles of Pax3

As a control Pax3 reporter mouse, we first generated a $P_{a x} 3^{I R E S n L a c Z}$ allele (Fig. 1A), in which IRESnLacZ replaces exon 2, which contains the $5^{\prime}$ part of the paired domain. The $n L a c Z$ reporter gene faithfully reproduces the expression of the endogenous gene in vivo, as revealed by in situ hybridization (Fig. 1C,D). Furthermore these mice display the wide range of heterozygous and homozygous Pax3 mutant (Splotch, Sp) phenotypes (Auerbach 1954) when intercrossed (data not shown; see Fig. 2A,B).

We engineered a conditional Pax $3^{\text {PAX3-FKHR-IRESnLacZ }}$ allele by replacing the first exon of $P a x 3$ with a floxed puro-poly $(A)^{+}$cassette followed by a dicistronic PAX3FKHR-IRESnLacZ cDNA to be able to follow cells expressing the human fusion sequence, $P A X 3-F K H R$, in vivo (Fig. 1B). In this case, exon 1 was targeted to avoid creating a fusion protein. The $\operatorname{Pax} 3^{P u r o(P A X 3-F K H R-I R E S n L a C Z) /+}$ animals [with the floxed puro-poly $(A)^{+}$cassette blocking 

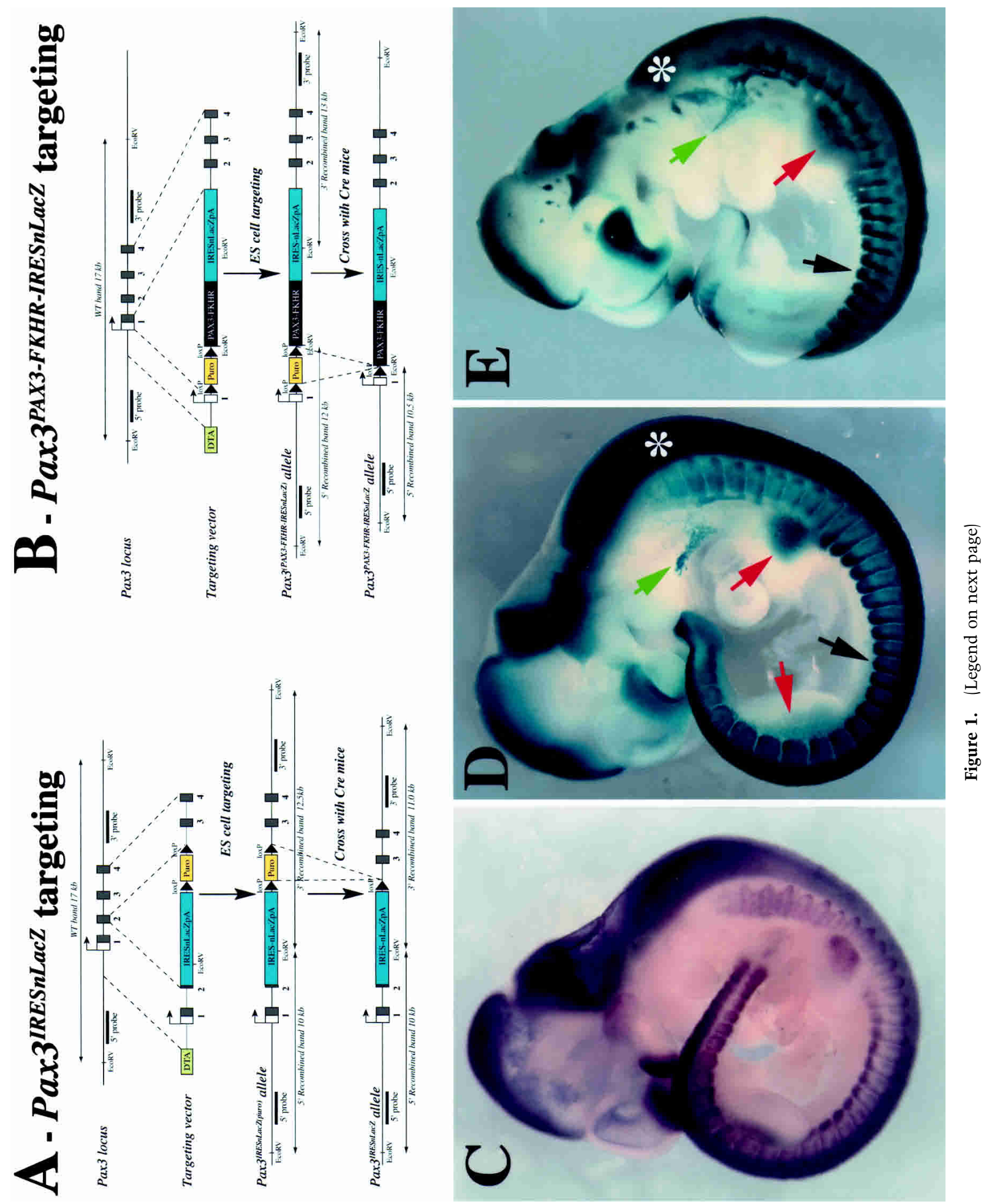
expression of PAX3-FKHR-IRESnLacZ] are viable and fertile and display the expected heterozygous Splotch phenotypes, similarly to mice with the Pax $3^{\text {IRESnLacZ }}$ allele. However, when crossed with an ubiquitously expressing PGK-Cre mouse (Lallemand et al. 1998), to produce $P a x 3^{\text {PAX3-FKHR-IRESnLacZ/+ }}$ animals, no live newborn heterozygotes were obtained. This suggests that early expression of $P A X 3-F K H R$ leads to embryonic lethality. We first verified that the $P A X 3-F K H R$ allele was correctly expressed by comparing the expression profile of Pax $3^{\text {IRESnLacZ/+ }}$ with that of Pax3 ${ }^{\text {PAX3-FKHR-IRESnLacZ/+. }}$. $\beta$-Galactosidase ( $\beta$-Gal) activity shows that the allele with $P A X 3-F K H R$ reproduces $P a x 3$ expression during development (Fig. 1E).

\section{The PAX3-FKHR fusion protein is able to rescue Pax3 mutant phenotypes}

To investigate the function of $\operatorname{Pax} 3$ as a transcriptional activator or repressor during development, we crossed the Pax $3^{\text {PAX3-FKHR-IRESnLacZ/+ }}$ line with $\mathrm{Pax}^{\mathrm{Sp} /+}$ mice to establish whether the Pax3 ${ }^{P A X 3-F K H R-I R E S n L a c Z /+}$ allele, as a gain-of-function mutation, is able to rescue the defects in the Pax3 mutants. Pax $3^{\text {IRESnLacZ/Splotch }}$ compound mutant embryos have the expected Splotch phenotype, as shown by X-Gal staining compared with the control Pax $3^{\text {IRESnLacZ/+ }}$ embryos. This includes segmentation defects, abnormalities in the epaxial and hypaxial dermomyotome, lack of limb muscles, spina bifida, and to a lesser extent, exencephaly (Fig. 2, cf. B and A). In addition there is a lack of neural crest cell migration (Fig. 2 , cf. $\mathrm{B}^{\prime}$ and $\mathrm{A}^{\prime}$ ), which leads to the absence of dorsal root ganglia (Fig. 2, cf. $\mathrm{B}^{\prime \prime}$ and $\mathrm{A}^{\prime \prime}$ ). In Pax3 ${ }^{P A X 3-F K H R-I R E S n L a c Z /+}$ embryos, the boundaries between hypaxial somites are disorganized (Fig. 2C, red arrow), but they do not show any of the defects due to Pax3 deficiency observed in Figure 2B. This indicates that PAX3-FKHR, produced under normal Pax3 regulation, does not antagonize or interfere with the function of Pax3, as previously suggested (Anderson et al. 2001).
Strikingly, in the absence of Pax3, Pax $3^{\text {PAX3-FKHR-IRESnLacZ/Sp }}$ embryos present a phenotype (Fig. 2D-D") similar to that of Pax3 ${ }^{\text {PAX3-FKHR-IRESnLacZ/+ }}$ embryos (Fig. 2C-C") without the defects that characterize Splotch mutants (cf. Fig. 2B-B"). This result shows that $P A X 3-F K H R$ is able to rescue the early Pax3 mutant phenotype, acting as a gain-of-function mutation. This suggests that Pax 3 acts mainly as a transcriptional activator in the embryo.

Confirmation of this conclusion is provided by a Pax3 reporter embryo. A consensus Pax3-binding site (Epstein et al. 1996) was concatamerized (five times) in front of a $T K$ promoter driving an nlacZ reporter. This transgene will only be expressed at sites where Pax3 is present, if this factor acts in vivo as a transcriptional activator. Transgenic embryos (embryonic day 10.5 [E10.5], $n=$ $3 / 5)$ have $\beta$-galactosidase-positive $\left(\beta-\mathrm{Gal}^{+}\right)$cells in the somites, limb buds, dorsal neural tube, and dorsal root ganglia, demonstrating Pax3 activation in vivo (Fig. 2E,F). Additional labeling corresponds to sites where other Pax genes are known to be expressed, in the neural tube, for example, or in the ventral somite, where Pax1 and $\operatorname{Pax} 9$ are present in the sclerotome, indicating that the Pax 3 consensus site is also recognized by other members of the family. The expression of $\mathrm{Pax} 7$, the ortholog of Pax3, overlaps with that of Pax3. In subdomains of the somite, for example, Pax 7 may be responsible for part of the reporter activation observed. However, $\mathrm{Pax} 7$ transcripts and protein are not detectable at other sites of Pax3 expression such as the hypaxial dermomyotome or in muscle progenitors migrating to the limb (Jostes et al. 1990; F. Relaix and M. Buckingham, in prep.), where the reporter transgene is activated.

PAX3-FKHR expression induces ectopic long-range migration of myogenic precursor cells, leading to somite, muscle, and rib defects

At E11.5, Pax3 $3^{\text {PAX3-FKHR-IRESnLaCZ/+ }}$ heterozygous embryos show disorganization of the hypaxial domain of

Figure 1. Targeting strategies and expression of the Pax3 alleles. (A) Schematic diagram of the targeted Pax ${ }^{I R E S n L a c Z}$ allele. The $5^{\prime}$ part of the Pax3 gene contains exons 1-4 (the gene spans $100 \mathrm{~kb}$ and contains eight exons). We targeted an IRESnLacZ sequence followed by the SV40 polyadenylation sequence and a floxed puromycin-pA selection cassette, into exon 2 of Pax3 by homologous recombination in embryonic stem (ES) cells. A counterselection cassette encoding the A subunit of Diphtheria Toxin (DTA) was inserted at the $5^{\prime}$-end of the vector. The probes and restriction enzymes are indicated, as well as the size of the resulting wild-type and recombined restriction fragments. We chose to target the $n L a c Z$ reporter gene into exon 2 in order to inactivate the paired DNAbinding domain. The Pax $3^{I R E S n L a c Z(p u r o)}$ allele was crossed with a PGK-Cre mouse (Lallemand et al. 1998) to remove the Puromycin selection cassette, leaving a single Lox $P$ site $3^{\prime}$ of IRESnLacZpA in the final Pax $3^{\text {IRESnLacZ }}$ allele. (B) Schematic diagram of the targeted conditional Pax3 ${ }^{P A X 3-F K H R-I R E S n L a c Z}$ allele. The $5^{\prime}$ part of the Pax3 locus is indicated as in $A$. In the targeting vector, the floxed puromycin- $p A$ selection marker replaces the coding sequence in exon 1 of $P a x 3$, followed by a dicistronic cassette containing the human PAX3-FKHR coding region followed by an IRESnLacZpA cassette, in order to be able to follow the expression of the allele. The probes and restriction enzymes are indicated, with the size of the resulting wild-type and recombined restriction fragments. After homologous recombination, PAX3-FKHR-IRESnLacZ expression from the Pax3 Puro(PAX3-FKHR-IRESnLacZ) allele is blocked by the floxed puromycin-pA cassette and is therefore conditional to removal by crossing with a Cre mouse (Lallemand et al. 1998). As Pax3 $3^{\text {PAX3-FKHR-IRESnLacZ } /+}$ heterozygotes are not viable, the mice were maintained as Pax3 $3^{\text {Puro(PAX3-FKHR-IRESnLacZ)/+. }}$ (C,D) Expression of $n L a c Z$ revealed by X-Gal staining $(D)$ compared with expression of endogenous Pax3, visualized by in situ hybridization $(C)$, at E10.5 shows that IRESnLacZ is correctly expressed in the Pax $3^{I R E S n L a c Z /+}$ embryos, in the dermomyotome and myotome of the somites (black arrow), limb buds (red arrows) and hypoglossal chord (green arrow), fronto-nasal masses and olfactory epithelium, and dorsal

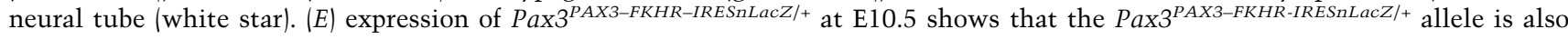
expressed in somites (black arrow), limb buds (red arrows) and hypoglossal chord (green arrow), fronto-nasal masses and olfactory epithelium, and dorsal neural tube (white star). 

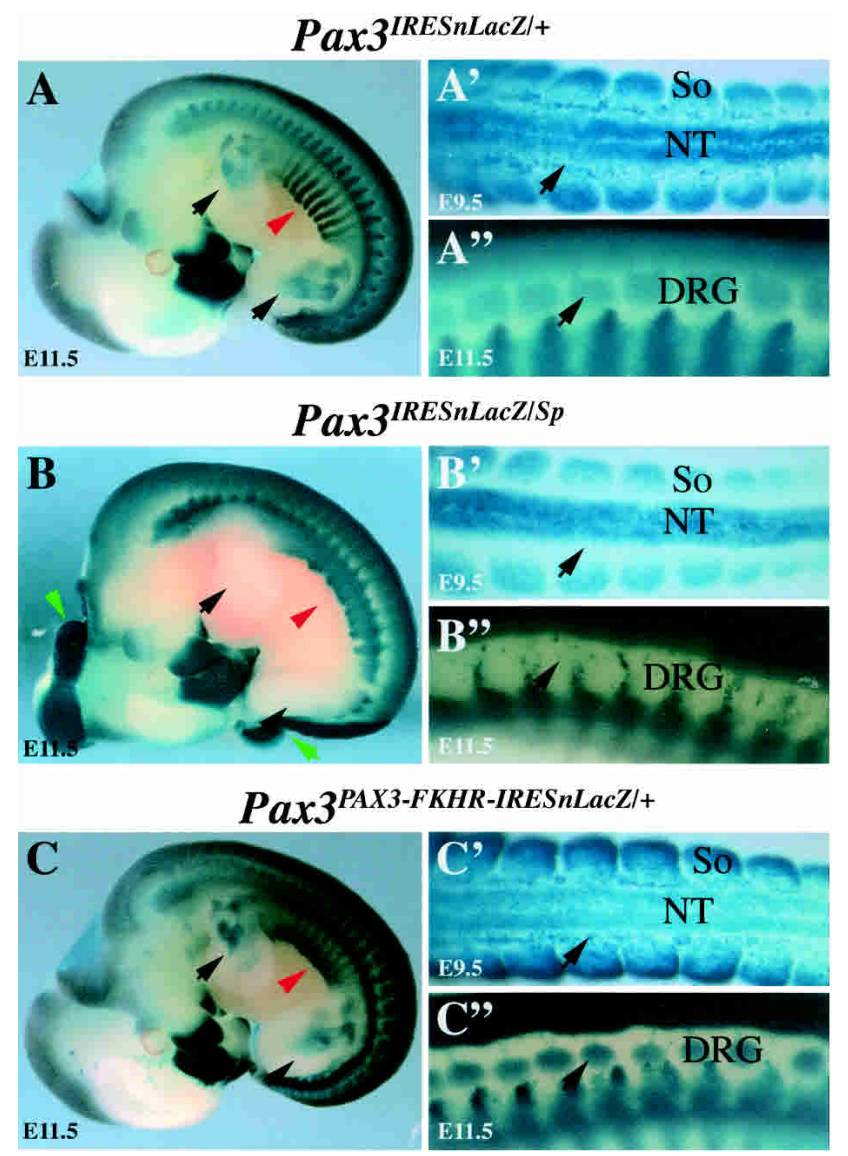

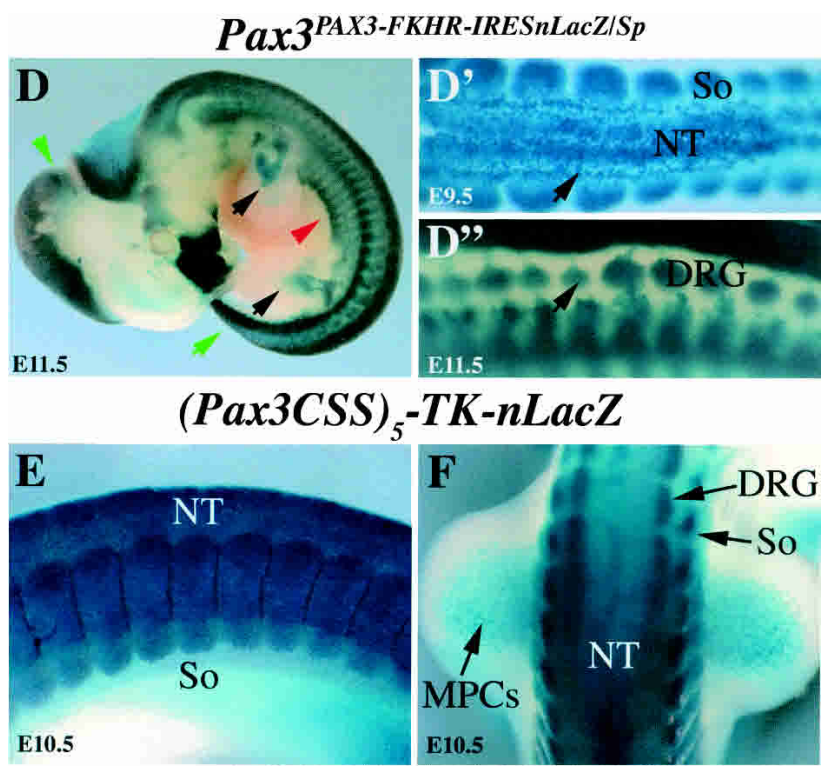

Figure 2. PAX3-FKHR rescues Pax3 mutant defects. Embryos were stained with X-Gal to reveal $\beta$-Gal activity in cells that express nlacZ from the targeted allele of Pax3. (A) A Pax $3^{I R E S n L a c Z /+}$ embryo at E11.5. Limb muscles (black arrow) and the hypaxial region of interlimb somites (red arrowhead) are indicated. (B) A Pax3 $3^{I R E S n L a c Z / S p}$ compound mutant embryo at E11.5. The phenotype is identical to homozygous Splotch (Auerbach 1954) or Pax3 $3^{I R E S n L a c Z / I R E S n L a c Z}$ mutants; one allele of $n L a c Z$ facilitates comparison with heterozygotes as shown in $A$. Note the exencephaly and spina bifida (green arrows), absence of limb muscles (black arrow), and fused and truncated somites (red arrowhead) when compared with $A$. $(C)$ A Pax3 ${ }^{P A X 3-F K H R-I R E S n L a c Z /+}$ embryo at E11.5. Limb muscles (black arrows) and disorganized hypaxial somites (red arrowhead) are indicated. (D) A Pax3 ${ }^{P A X 3-F K H R-I R E S n L a c Z / S P}$ compound mutant embryo at E11.5. The phenotype is almost identical to that of the $P a \times 3^{\text {PAX3-FKHR-IRESnLacZ/+ }}$ embryo at the same stage (cf. C), indicating that the Pax $3^{\text {PAX3-FKHR-IRESnLacZ/+ }}$ allele is dominant over that of Pax3. Many of the early phenotypes observed in the Pax3 ${ }^{I R E S n L a c Z / S p}$ compound mutant embryo $(B)$ are rescued, such as absence of limb muscles (black arrow), or disorganized and truncated somites (red arrowhead). ( $\left.A^{\prime}-D^{\prime}\right)$ Dorsal views of E9.5 embryos showing the neural tube from which neural crest cells normally migrate (back arrow). The defect in Pax3 mutant embryos $\left(B^{\prime}\right)$ is rescued in the $P a x 3^{P A X 3-F K H R-I R E S n L a c Z / S p}$ compound mutant embryos, where neural crest cells are present $\left(D^{\prime}\right) \cdot\left(A^{\prime \prime}-D^{\prime \prime}\right)$ Lateral views of E11.5 embryos showing dorsal root ganglia (black arrow). Their failure to form in the Pax3 mutant embryos $\left(B^{\prime \prime}\right)$ is rescued in the Pax3 ${ }^{\text {PAX3-FKHR-IRESnLacZ/SP }}$ compound mutant embryos $\left(D^{\prime \prime}\right)$. (E,F) A (Pax3CSS) $)_{5}$ TK-nlacZ transgenic embryo at E10.5 shows expression of the reporter with $\beta$-Gal-positive cells in the neural tube, dorsal root ganglia, somites, and limb buds. (So) Somites; (NT) neural tube; (DRG) dorsal root ganglia; (MPC) muscle progenitor cells.

the somites (Fig. 2C), and we therefore investigated the phenotype of these mice at earlier stages (Fig. 3).

At E10.5, in Pax3 $3^{I R E S n L a c Z /+}$ embryos, $\beta$-Gal activity is high along the caudal edge and in the hypaxial domain of the dermomyotome (Fig. 3A). In contrast, in

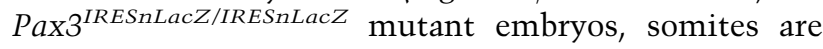
disorganized and truncated in the hypaxial and epaxial domains (Fig. 3B). In Pax3 ${ }^{\text {PAX3-FKHR-IRESnLaCZ/+ }}$ embryos, the full extent of the somite is present (Fig. 3C), but the hypaxial region is disorganized with abnormal delamination of $\beta-\mathrm{Gal}^{+}$cells (Fig. 3, cf. F and D). Transverse sections of $P a \times 3^{\text {PAX3-FKHR-IRESnLacZ/+ }}$ somites at this stage reveal a complete loss of the hypaxial epithelium of the dermomyotome, which forms the so-called somitic bud in thoracic somites, and the presence of ectopic $\beta$-Gal ${ }^{+}$ cells outside the somite (Fig. 3, cf. G and E, arrows).

To visualize directly the cellular structure of the der-

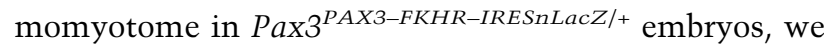
performed coimmunohistochemistry on transverse sections of thoracic somites from control (Fig. $3 \mathrm{H}, \mathrm{I})$ and mutant (Fig. 3J,K) embryos. A schematic section of a normal somite is shown in Figure 3L for comparison. In normal somites, the basal lamina, revealed by an antiLaminin antibody, is located around the dermomyotome and myotome, separating these two somite compartments (Fig. 3I, yellow arrowhead, 3L) and delimiting the hypaxial extremity of the former (Fig. 3I, white arrowhead, 3L). As expected, $\beta$-Gal ${ }^{+}$cells, synonymous with Pax3 expression, are present in the epithelial dermomyotome, especially in the hypaxial domain $($ Fig. $3 \mathrm{H}$, white arrowhead, $3 \mathrm{~L}$ ), but also in the central region of the dermomyotome, which at this stage (E10.75, 36 somites) is losing its epithelial structure, and in the myotome, where some of the labeling may be due to the perdura- 

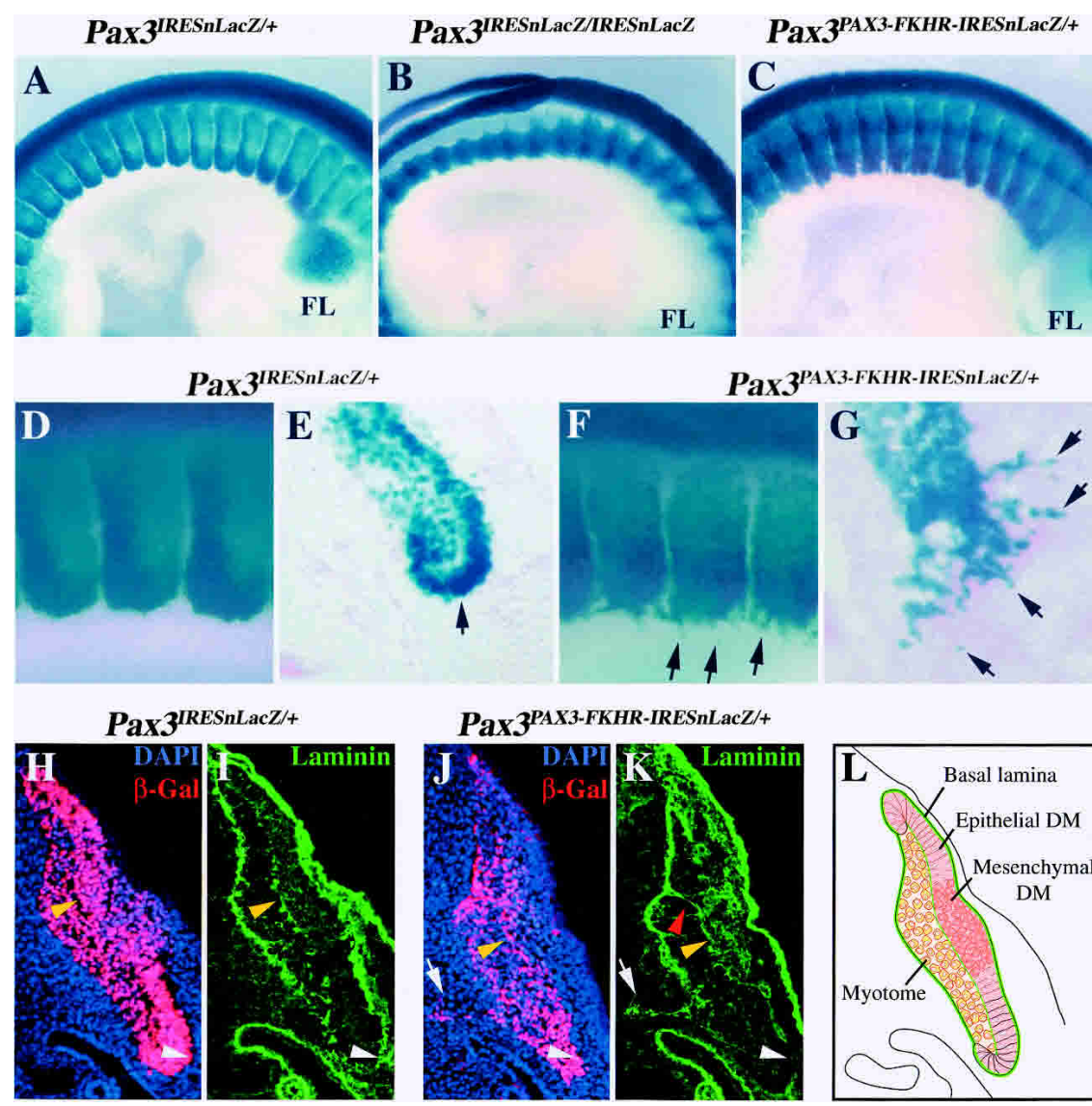

$\operatorname{Pax} 3^{P A}$

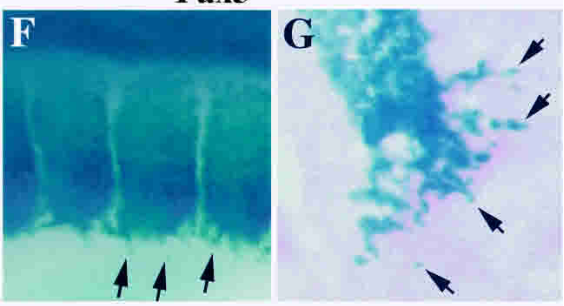
the somite (black arrows). (H-K) Immunohistochemistry on transverse sections of thoracic somites from E10.5 Pax $3^{I R E S n L a c Z /+}(H, I)$ or Pax ${ }^{\text {PAX3-FKHR-IRESnLacZ/+ }}$ embryos $(J, K)$, using antibodies recognizing Laminin $(I, K)$ or $\beta$-galactosidase (with DAPI staining; $\left.H, J\right)$, shows that the somite structure is perturbed in Pax $3^{\text {PAX3-FKHR-IRESnLacZ } /+}$ embryos compared with Pax $3^{I R E S n L a c Z /+}$ embryos, with reduction of the basal lamina of the hypaxial dermomyotome (white arrowhead), defects (yellow arrowhead), and fusions (red arrowhead) of the basal lamina separating dermomyotome and myotome. Furthermore, cells mislocated ventrally can be identified $(J, K$, white arrow $)$. $(L)$ Schematic transverse section showing mouse somite organization at E10.75.

tion of the $\beta$-Gal protein (see Hadchouel et al. 2000). In $P a x 3^{P A X 3-F K H R-I R E S n L a c Z /+}$ embryos, the structure of thoracic somites is disorganized (Fig. 3, cf. J,K and H,I,L), and the epithelial structure of the dermomyotome is perturbed with defects in the basal lamina, which shows gaps (white arrowhead), fusions (red arrowhead), and abnormal accumulation of Laminin (Fig. 3, cf. K and I,L). In the mutant, the hypaxial dermomyotome is not clearly separated from the myotome with a lack of basal lamina in the hypaxial domain. Furthermore, $\beta-\mathrm{Gal}^{+}$cells /and Laminin deposits) are present ectopically, ventral to the hypaxial domain (arrow).

These data suggest that PAX3-FKHR induces an epithelial-to-mesenchymal transition of the hypaxial dermomyotome, similar to that normally observed only in somites at the level of the limbs and hypoglossal cord, with disorganization of the hypaxial myotome.

Cells that had delaminated in the thoracic region, distant from the limb fields, are apparently unable to migrate and stay in the vicinity of the somites as seen at E11.5 by $\beta$-Gal ${ }^{+}$labeling (Fig. 4A,B). These cells, mainly located in the hypaxial region of the somites and in the epaxial-most domain, where $P a x 3$ expression levels are
Figure 3. PAX3-FKHR induces abnormal delamination and loss of somite structure. $(A-C) \mathrm{X}$-Gal staining of cells expressing the nlacZ reporter gene in the targeted Pax3 allele reveals defects in the thoracic somites of E10.5 (32 somites) Pax3 ${ }^{\text {IRESnLacZ/IRESnLacZ }}$ $(B)$ and Pax3 $3^{\text {PAX3-FKHR-IRESnLacZ }}(C)$ embryos compared with control Pax3 ${ }^{\text {IRESnLacZ/+ }}$ embryos $(A)$. Note the somite disorganization and hypaxial and epaxial truncations in Pax3 $3^{\text {IRESnLacZ/IRESnLacZ }}$ mutant embryos, which also show spina bifida $(B) .(C)$ PaX3 ${ }^{\text {PAX }-F K H R-I R E S n L a c Z}$ embryos have $\beta-\mathrm{Gal}^{+}$cells located between the somites and around the hypaxial extremity. (FL) Forelimb bud. $(D, F)$ Closeup views of the thoracic somites of E10.5 Pax $3^{\text {IRESnLacZ/+ }}$ $(D)$ or Pax3 $3^{\text {PAX3-FKHR-IRESnLacZ/+ }}(F)$ embryos, stained with X-Gal, show delamination from the hypaxial region of the somite in the presence of the PaX $3^{\text {PAX3-FKHR-IRESnLacZ/+ }}$ allele. Cells that have moved away from the hypaxial somites are indicated (black arrows). Within the somites, the nlacZ expression pattern is perturbed (Fig. 3C). The anterior of the embryos is on the right. $(E, G)$ Transverse sections of an E10.75 Pax3 ${ }^{\text {IRESnLacZ } /+}$ $(E)$ or a $P a x 3^{\text {PAX3-FKHR-IRESnLacZ/+ }}(G)$ embryo, after staining for $\beta$-Gal activity. Pax3 ${ }^{\text {PAX3-FKHR-IRESnLacZ/+ }}$ embryos show disruption of the epithelium of the hypaxial dermomyotome with cells leaving

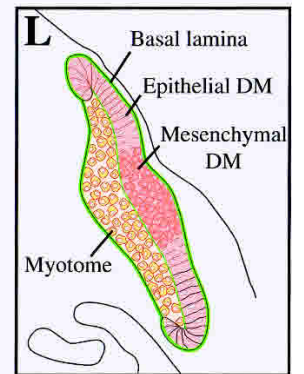

normally highest, activate the myogenic program as visualized by the muscle differentiation marker, cardiac $\alpha$-actin (Fig. 4C,D). This ectopic muscle differentiation, together with the disruption of the hypaxial myotome, leads to disorganization of the intercostal muscles and loss of ventral body muscles at E12.5 (Fig. 4E,F). Pax3 ${ }^{P A X 3-F K H R-I R E S n L a c Z /+}$ fetuses have distal rib defects as revealed by Alizarin red-Alcian blue staining of the bone and cartilage at E18.5 (Fig. 4G,H). This may result from the malformation of the associated muscles or from the early disorganization of the hypaxial (dermo)myotome affecting the underlying sclerotome from which the distal ribs form (see Tajbakhsh and Buckingham 2000; Evans 2003).

Abnormal activation of myogenic factors in migrating muscle precursor cells, due to ectopic somite participation

Myogenic progenitor cells, which have undergone abnormal delamination, remain in the vicinity of the thoracic somites and subsequently contribute to the disorganization of the trunk muscles in Pax3 ${ }^{\text {PAX3-FKHR-IRESnLaCZ/+ }}$ 

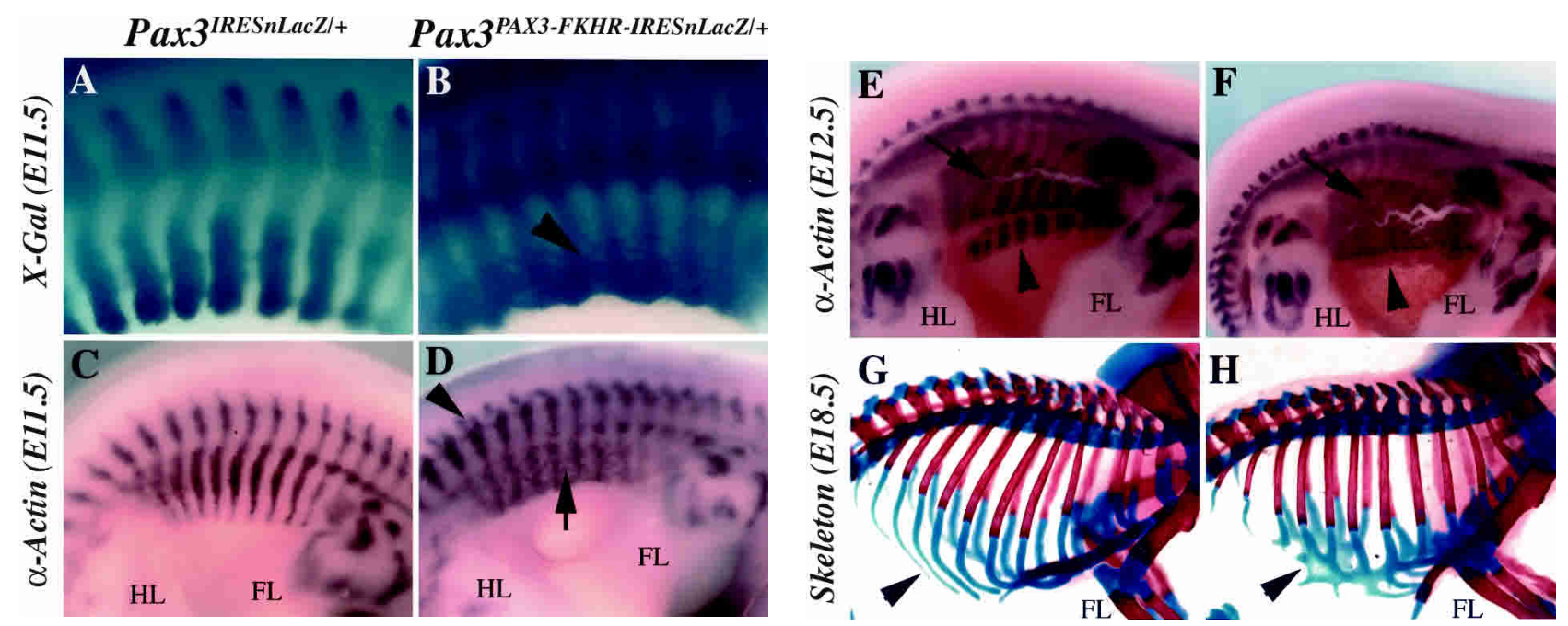

Figure 4. Body muscles and ribs are perturbed in Pax3 ${ }^{P A X 3-F K H R-I R E S n L a c Z /+}$ embryos. $(A, B) \mathrm{X}$-Gal staining of thoracic somites at E11.5 in $\operatorname{Pax}^{I R E S n L a c Z /+}(A)$ and $\operatorname{Pax}^{\text {PAX3-FKHR-IRESnLacZ } /+}(B)$ embryos. Dispersed $\beta$-Gal ${ }^{+}$cells remain adjacent to the somites in $P a x 3^{\text {PAX3-FKHR-IRESnLacZ } /+}$ embryos, and are particularly evident in the hypaxial region $(B$, black arrowhead). $(C, D)$ The presence of the myogenic differentiation marker, $\alpha$-actin, at E11.5 in Pax $3^{I R E S n L a c Z /+}(C)$ and Pax $3^{\text {PAX3-FKHR-IRESnLacZ/+ }}(D)$ embryos shows that dispersed cells that have undergone abnormal delamination are also terminally differentiated both epaxially $(D$, black arrowhead $)$ and hypaxially $\left(D\right.$, black arrow). In the Pax $3^{I R E S n L a c Z /+}$ control, $\alpha$-actin-positive cells are confined to the myotome $(C)$. $(E, F)$ Expression of $\alpha$-actin at E12.5 marks all the well-defined differentiated muscle masses of control Pax $3^{\text {IRESnLacZ/+ }}$ embryos $(E)$. In contrast, in $P a \times 3^{P A X 3-F K H R-I R E S n L a c Z /+}$ embryos $(F)$, intercostal muscle masses are disorganized $(F$, black arrow; cf. $E)$, and the segmental form of the rectus-abdominis muscle is no longer distinguishable $(F$, black arrowhead). $(G, H)$ Alizarin red-Alcian blue staining of bone and

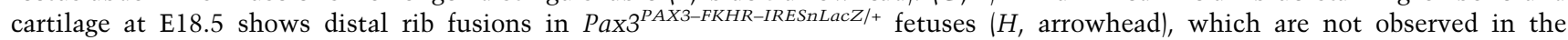
Pax3 $^{\text {IRESnLacZ/+ }}$ controls at the same stage $(G$, arrowhead). (FL) Forelimb; (HL) hindlimb.

fetuses. However $\beta$-Gal ${ }^{+}$cells from somites adjacent to those that normally contribute cells to the hypoglossal cord or limb buds, now also migrate into these areas. This is shown in Figure 5 for the forelimb bud of PaX3 $3^{\text {PAX3-FKHR-IRESnLacZ/+ }}$ (Fig. 5B) compared with Pax $3^{\text {IRESnLacZ/+ }}$ (Fig. 5A) embryos at E10.25, and summarized in Figure 5Q. Unlike the normal situation in which the myogenic determination factor genes $M y o D$ and Myf5 are not expressed until the migratory muscle progenitor cells reach the limb (Fig. 5C,E,G; Sassoon et al. 1989; Tajbakhsh and Buckingham 1994), in Pax ${ }^{\text {PAX3-FKHR-IRESnLacZ/+ }}$ embryos, MyoD-positive (Fig. 5D,F) and Myf5-positive (Fig. 5H) cells extend from peripheral somites into the limb buds. This includes somites that contribute both to limb and body wall muscles as well as those that normally make no contribution to the limb. This probably reflects the ectopic delamination of myogenic cells in the hypaxial dermomyotome of cervical and thoracic somites where Myf5 and $M y o D$ are already activated. These cells, like those from somites opposite to limb buds that delaminate normally, are now also attracted into the limb field. Despite an ectopic contribution of predetermined myogenic cells, the perturbations that this may produce in the formation and patterning of the limb muscles are no longer detectable at later stages. This is shown at E11.5 for the forelimb with a muscle $\alpha$-actin marker (Fig. 5I,J) and at E12.5 with MyoD as a muscle marker for the hindlimb (Fig. 5K,L). Similarly in the cervical region, where the somites are clearly disorganized and the myotomal muscle shows bifurcations (Fig. 5M,N), by E12.5 the cervical muscles are largely normal (Fig. 5O,P). This is in contrast to the thoracic region and suggests that in the neck and limbs compensatory mechanisms are able to rescue initial defects caused by aberrant behavior of myogenic cells in the presence of PAX3-FKHR.

\section{Ligand-independent Met signaling mediates PAX3-FKHR phenotypes in thoracic somites}

Because the tyrosine kinase receptor, Met, plays a critical role in epithelial/mesenchymal transitions and in the migration of myogenic precursor cells (Bladt et al. 1995), we performed in situ hybridization on PaX3 ${ }^{\text {PAX3-FKHR-IRESnLacZ/+ }}$ embryos at E10.5 using a cmet probe. These experiments showed that c-met is widely overexpressed in the somites (Fig. 6B) compared with the normal situation, where accumulation of c-met transcripts is confined to the hypaxial somitic bud, with transcripts detectable in the epaxial extremity of rostral somites at E10.5 (Fig. 6A). c-met is also expressed at a high level in muscle progenitor cells in the limb buds (Fig. 6A,B). Overexpression of c-met in the somite corresponds to sites of high Pax3, and hence PAX3-FKHR transcription, as seen along the caudal edge as well as in the hypaxial part of the dermomyotome (Fig. $6 \mathrm{~B}^{\prime}$; cf. Fig. 3D). c-met is also activated in the dorsal neural tube of

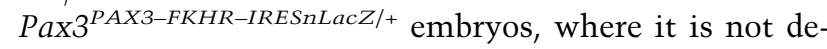
tectable in control embryos (Fig. 6A,B). These findings indicate that c-met is a Pax3 target in vivo and show that 

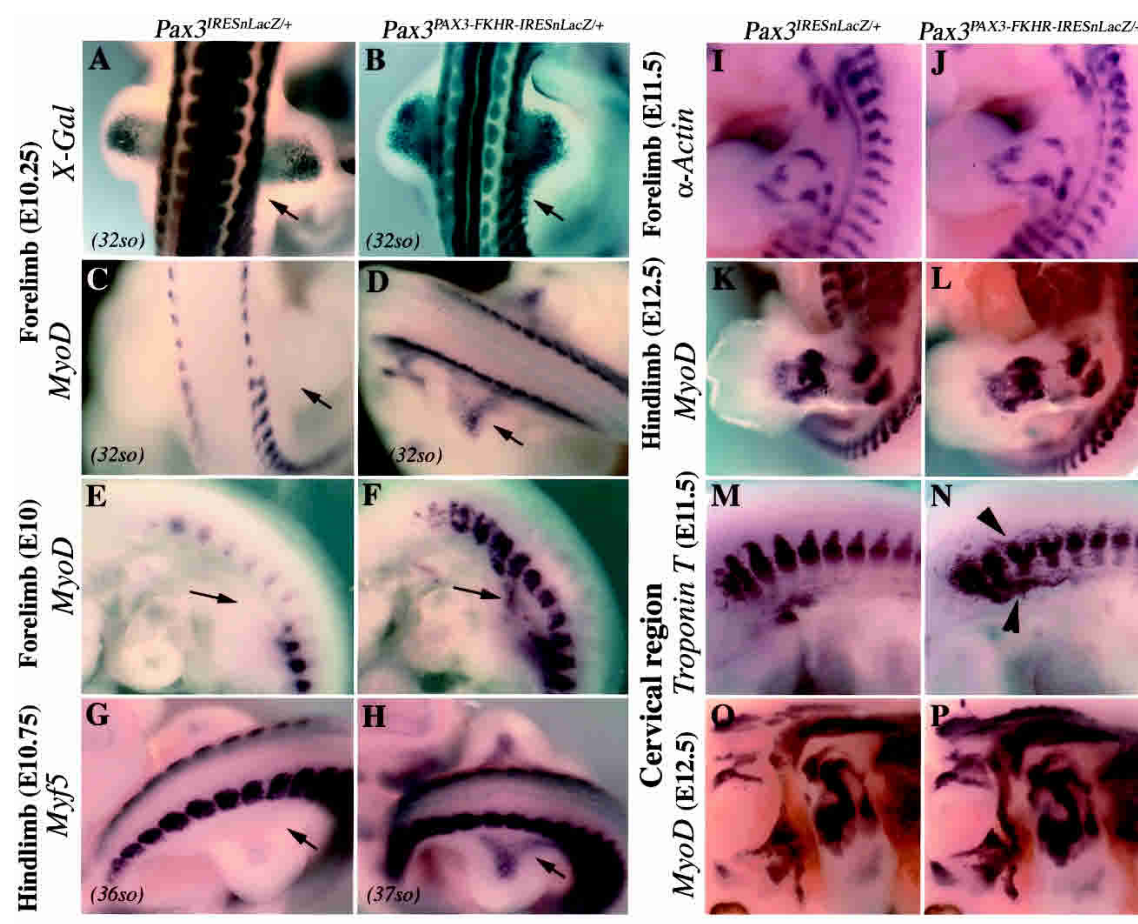

Q

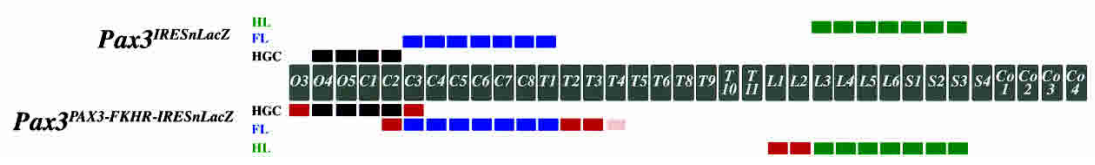

Figure 5. PAX3-FKHR induces ectopic migration of predetermined myogenic cells in the embryo. $(A, B) \mathrm{X}$-Gal-staining of migratory precursor cells colonizing the forelimbs at E10.25 in $\operatorname{Pax}^{I R E S n L a c Z /+}(A)$ and Pax3 ${ }^{\text {PAX3-FKHR-IRESnLacZ/+ }}$ embryos $(B)$. In the latter, the first two to three thoracic somites, which are not facing the limb bud, are now contributing to this population (arrow). This is not observed in the control embryo $(A)$, as previously shown (Houzelstein et al. 1999). $(C, D)$ $M y o D$ in situ hybridization shows that at this stage (E10.25, 32 somites), muscle progenitor cells migrating into the limb buds are not determined and do not express myogenic factors in the Pax $3^{I R E S n L a c Z /+}$ control embryo $(C$, arrow). However, at the same stage, Pax3 ${ }^{\text {PAX3-FKHR-IRESnLacZ/+ embryos have }}$ $M y o D$-expressing cells in the limb bud $(D$, arrow). $(E, F) M y o D$ in situ hybridization shows that at E10 (30 somites), Pax3 ${ }^{\text {PAX3-FKHR-IRESnLacZ/+ }}$ embryos have $M y o D$-positive cells adjacent to the thoracic and cervical somites (black arrow) and in the forelimb $(F)$. This is not observed in the control embryo $(E)$. $(G, H)$ Myf5 in situ hybridization on hindlimb buds of Pax $3^{\text {IRESnLacZ } /+}$ embryos $(G)$ shows that at E10.75, Myf5 transcripts are first detectable in centrally located cells, whereas in $P a x 3^{\text {PAX3-FKHR-IRESnLacZ/+ }}$ embryos $(H)$ at this stage, in the presence of PAX3-FKHR, expression of Myf5 is much more extensive. Somite numbers (so) are indicated. $(I, J)$ Expression of the myogenic differentiation marker, $\alpha$-actin at E11.5, in the forelimb of $\operatorname{Pax}^{\text {IRESnLacZ } /+}(I)$ and Pax $3^{\text {PAX3-FKHR-IRESnLacZ } /+}(J)$ embryos, shows that at this stage, muscle patterning and differentiation are normal in Pax3 ${ }^{P A X 3-F K H R-I R E S n L a c Z /+}$ embryos (J), compared with the control $(I) .(K, L)$ MyoD in situ hybridization shows that at E12.5, muscle patterning in the hindlimb of a Pax3 ${ }^{\text {PAX3-FKHR-IRESnLacZ/+ }}$ embryo $(L)$ is normal compared with that in a Pax3 $3^{I R E S n L a c Z /+}$ embryo $(K) .(M, N)$ Expression of the myogenic differentiation marker, Troponin T, visualized by whole-mount immunohistochemistry at E11.5 in the occipital/cervical region of $P$ ax $3^{\text {IRESnLacZ/+ }}(M)$ and Pax3 ${ }^{\text {PAX3-FKHR-IRESnLaCZ/+ }}(N)$ embryos shows that cervical somites are disorganized (black arrowheads) in Pax ${ }^{\text {PAX3-FKHR-IRESnLacZ/+ }}$ embryos. $(O, P)$ Visualization of transcripts of the myogenic marker, $M y o D$, by in situ hybridization at E12.5 shows that muscles in the cervical region (and forelimb) are patterned normally in Pax3 ${ }^{\text {PAX3-FKHR-IRESnLacZ/+ }}(P)$ compared with Pax3 ${ }^{\text {IRESnLacZ/+ }}(O)$ embryos. (Q) Schema of somitic contribution [somites are numbered by type: $(\mathrm{O})$ occipital; $(\mathrm{C})$ cervical; $(\mathrm{T})$ thoracic; $(\mathrm{L})$ lumbar; $(\mathrm{S})$ sacral; (Co) coccyx] to the hypoglossal cord (HGC, black), forelimb (FL, blue), and hindlimb (HL, green), in Pax $3^{\text {IRESnLacZ/+ }}$ (above) and Pax $3^{\text {PAX3-FKHR-IRESnLacZ/+ }}$ (below) embryos. Additional contributing somites observed in Pax $3^{\text {PAX3-FKHR-IRESnLacZ/+ }}$ embryos are indicated in red. This is a dynamic process, and at any one time cells are migrating from a subset of the somites indicated.

PAX3-FKHR expression is sufficient to overactivate transcription of c-met, both in mesodermal and neurectodermal derivatives.

However, c-met activation by PAX3-FKHR was difficult to link to the ectopic delamination of cells from the dermomyotome observed in the Pax3 $3^{P A X 3-F K H R-I R E S n L a c Z /+}$ embryos (Fig. 3), because the ligand of Met, HGF/SF, is not expressed in the interlimb region (Bladt et al. 1995; Thery et al. 1995; Heymann et al. 1996), and we did not detect any ectopic expression of $H G F / S F$ in the

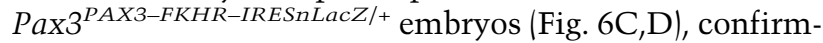
ing that $H G F / S F$ is not genetically linked to the Pax3c-met cascade. To establish whether c-met is involved in the Pax3 ${ }^{P A X 3-F K H R-I R E S n L a C Z /+}$ phenotype, we crossed these mice with mice heterozygous for a mutation that abrogates Met signaling $\left(\mathrm{c}-\mathrm{met}^{\mathrm{D} /+}\right.$, carrying a mutation in the two C-terminal tyrosines required for signaling (Maina et al. 1996), and produced $\mathrm{Pax}^{\text {PAX3-FKHR-IRESnLacZ/+ }} / \mathrm{c}-\mathrm{met}^{\mathrm{D} /+}$ double heterozygous embryos. Surprisingly, removing one allele of c-met was sufficient to abolish most of the ectopic somite delamination seen with the $\operatorname{Pax} 3^{P A X 3-F K H R-I R E S n L a c Z /+}$ allele (Fig. 6E; cf. Fig. 3D,F). In the presence of both mutant c-met alleles $\left(\mathrm{met}^{D / D}\right)$, the somitic phenotype of Pax3 ${ }^{\text {PAX3-FKHR-IRESnLaCZ/+ }}$ embryos was rescued (Fig. 6F). Thus, $P A X 3-F K H R$ expressed from the Pax3 locus is able to induce ligand-independent signaling from the Met receptor. This may occur through spontaneous Met dimerization as has been proposed previously in tumors expressing c-met at a high level (Bergstrom et al. 1999). 
Relaix et al.

Figure 6. Ligand-independent Met signaling mediates PAX3-FKHR activity in vivo. $(A, B)$ In situ hybridization using a c-met probe shows ectopic and enhanced expression of c-met in occipital/cervical (green arrowhead) and thoracic (red arrowhead) somites of E10.5 Pax3 ${ }^{\text {PAX3-FKHR-IRESnLacZ/+ }}$ embryos (B) compared with the Pax $3^{\text {IRESnLacZ/+ }}$ control embryos, where it is expressed in the epaxial and hypaxial extremities of the dermomyotome $(A)$. $\left(A^{\prime}, B^{\prime}\right)$ Closeups of c-met expression in thoracic somites. In both cases, c-met is expressed in limb muscle precursor cells (red arrowhead). $(C, D) \mathrm{SF} / \mathrm{HGF}$, the Met ligand, is not expressed in thoracic somites of Pax3 ${ }^{\text {IRESnLacZ/+ }}$ control embryos $(C$, black arrow $)$, nor is it induced in Pax3 ${ }^{\text {PAX3-FKHR-IRESnLacZ/+ }}$ embryos $(D$, black arrow). Normal expression in limb buds (red arrowheads) is also seen in Pax3 ${ }^{\text {PAX3-FKHR-IRESnLacZ/+ }}$ embryos (D) compared with the control $(C) .(E, F)$ Pax $3^{\text {PAX3-FKHR-IRESnLacZ/+ }}$ animals were crossed with c-met ${ }^{D /+}$ heterozygotes (Maina et al. 1996) to produce Pax3 ${ }^{\text {PAX3-FKHR-IRESnLaCZ/+ }} / \mathrm{c}-\mathrm{met}^{D /+}$ embryos $(E)$ and $P a \times 3^{\text {PAX3-FKHR-IRESnLacZ/+ } / \mathrm{c}-}$
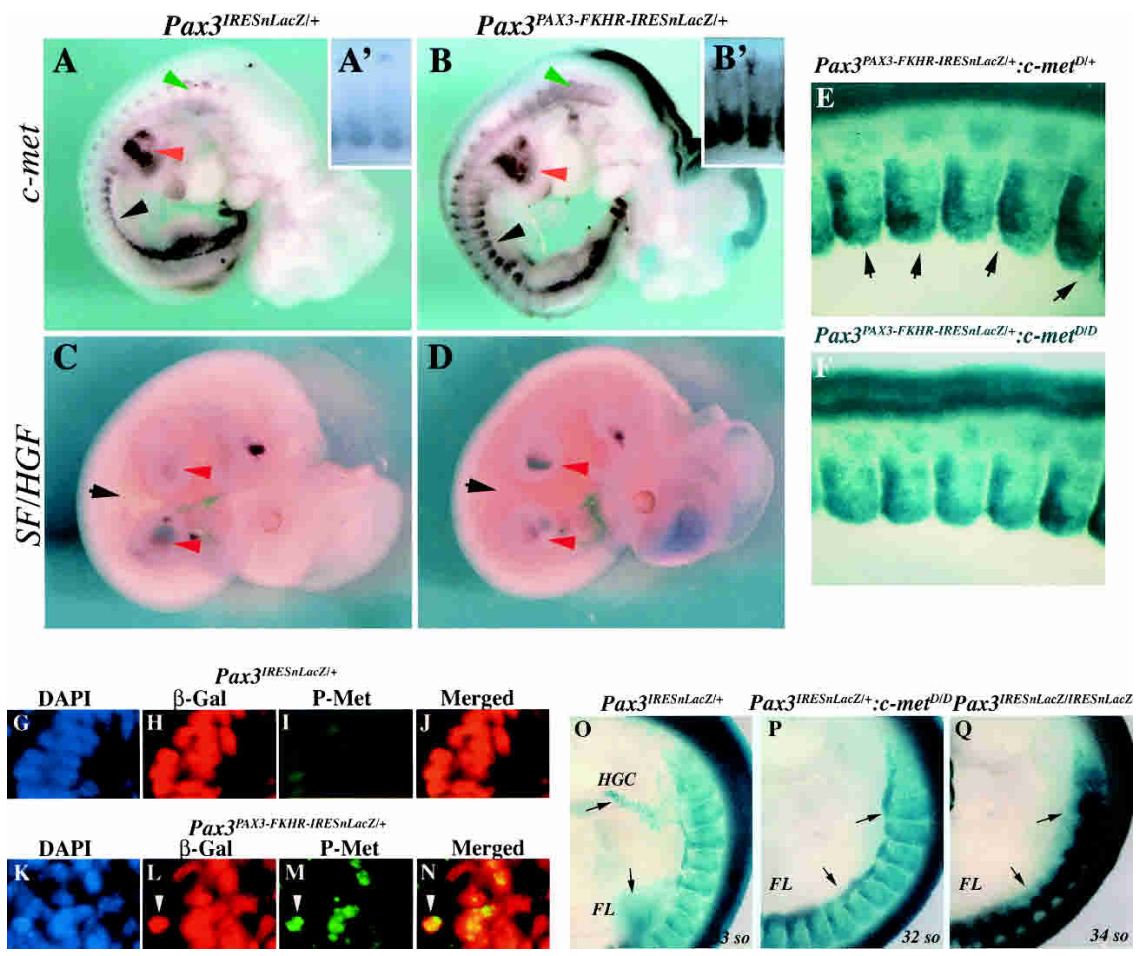

met $t^{D / D}$ embryos $(F)$. Reducing the number of c-met alleles suppresses in a dose-dependent manner the ectopic delamination gain-of-

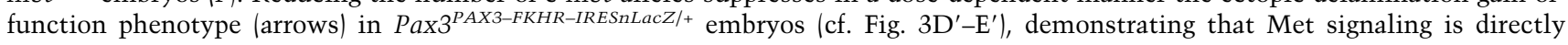
implicated in the phenotype. $(G-N)$ Immunocytochemistry on sections of thoracic level somites (closeup of the dermomyotome) from Pax ${ }^{I R E S n L a c Z /+}$ control $(G-J)$ or Pax3 ${ }^{\text {PAX3-FKHR-IRESnLacZ/+ }}$ embryos $(K-N)$ with DAPI staining $(G, K)$, using antibodies recognizing $\beta$-Gal $(H, L)$ or the form of Met phosphorylated on tyrosine 1234/12235 (P-Met) $(I, M)$. The merged images for $\beta$-Gal and P-Met are shown in $J$ and N. $\beta$-Gal-positive cells that coexpress P-Met are detected in the dermomyotome of the Pax3 ${ }^{\text {PAX3-FKHR-IRESnLacZ/+ }}$ somites only, demonstrating that Met is activated in the presence of PAX3-FKHR. Cells that have delaminated from the dermomyotome $(L-N$, white arrowhead) in Pax3 ${ }^{\text {PAX3-FKHR-IRESnLacZ/+ }}$ embryos also colabel with $\beta$-Gal and P-Met antibodies. (O-Q) X-Gal staining of the cervical region of Pax $^{\text {IRESnLacZ/+ }}(O, 33$ somites $)$, Pax $^{\text {IRESnLacZ/+ }} / \mathrm{c}-$ met $^{D / D}(P, 32$ somites $)$, and Pax $3^{\text {IRESnlacZIRESnLacZ/+ }}(Q, 34$ somites $)$ embryos at E10.5, shows maintenance of the full extent of the $\beta-\mathrm{Gal}^{+}$dermomyotome and in particular the hypaxial domain, in the absence of Met $(P$, arrows), compared with the Pax3 mutant (Q, arrows). (HGC) Hypoglossal cord; (FL) forelimb.

Activation of the Met kinase domain depends on the phosphorylation of tyrosine 1234/1235, which is diagnostic for the presence of activated Met (Longati et al. 1994). Using an antibody that specifically recognizes this phosphorylated form of Met, we detected staining in the $\beta$-Gal-positive cells of the dermomyotome of E10.5 Pax3 ${ }^{\text {PAX3-FKHR-IRESnLacZ/+ }}$ embryos at the interlimb level, and in cells that have delaminated from the dermomyotome (Fig. 6K-N). No labeling with this antibody was seen with control embryos (Fig. 6G-J). We therefore conclude that ligand-independent Met signaling leads to ectopic delamination of somitic cells as a result of an aberrant increase in c-met expression due to overactivation of the gene by PAX3-FKHR.

The $n L a c Z$ reporter gene in the Pax3 locus marks cells in the hypaxial dermomyotome (Fig. 6O) and shows that in $\mathrm{Pax}^{\text {IRESnLacZ/+}} / \mathrm{c}-\mathrm{met}^{D / D}$ embryos at E10.5, these cells are present (Fig. 6P). This is in contrast to the situation in Pax ${ }^{\text {IRESnLacZ/IRESnLacZ }}$ mutant embryos (Fig. $6 \mathrm{Q})$, in which this region of the dermomyotome is lost. This observation demonstrates that Met is not involved in the proliferation and maintenance of muscle progenitor cells in the dermomyotome, in accordance with pre- vious analysis of c-met mutants (Dietrich et al. 1999). Another target of Pax3 must prevent apoptosis in the hypaxial and epaxial extremities of this epithelium.

\section{PAX3-FKHR activates MyoD but not Myf5}

Because loss-of-function analyses in the mouse embryo had shown that $P a x 3$ lies genetically upstream of $M y o D$ but not Myf5 (Tajbakhsh et al. 1997), we investigated the effects of the gain-of-function $P a \times 3^{P A X 3-F K H R-I R E S n L a C Z}$ allele on $M y o D$ and Myf5 expression. In situ hybridization at E9.75 and E10.5 shows no major alteration in Myf5 transcripts, with the exception of the migrating cells that delaminate ectopically from thoracic somites close to the limb buds in Pax $3^{\text {PAX3-FKHR-IRESnLacZ/+ }} \mathrm{em}$ bryos at E10.5 (Fig. 7A-D, black arrow). Similarly to Myf5, MyoD transcription is initiated correctly (Fig. $7 \mathrm{G}, \mathrm{H})$. However, by E10.5, MyoD expression that is normally still restricted to the hypaxial myotome at this stage extends into the central domain of the somite in

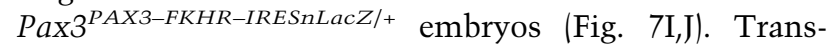
verse sections of thoracic somites from E10.5 

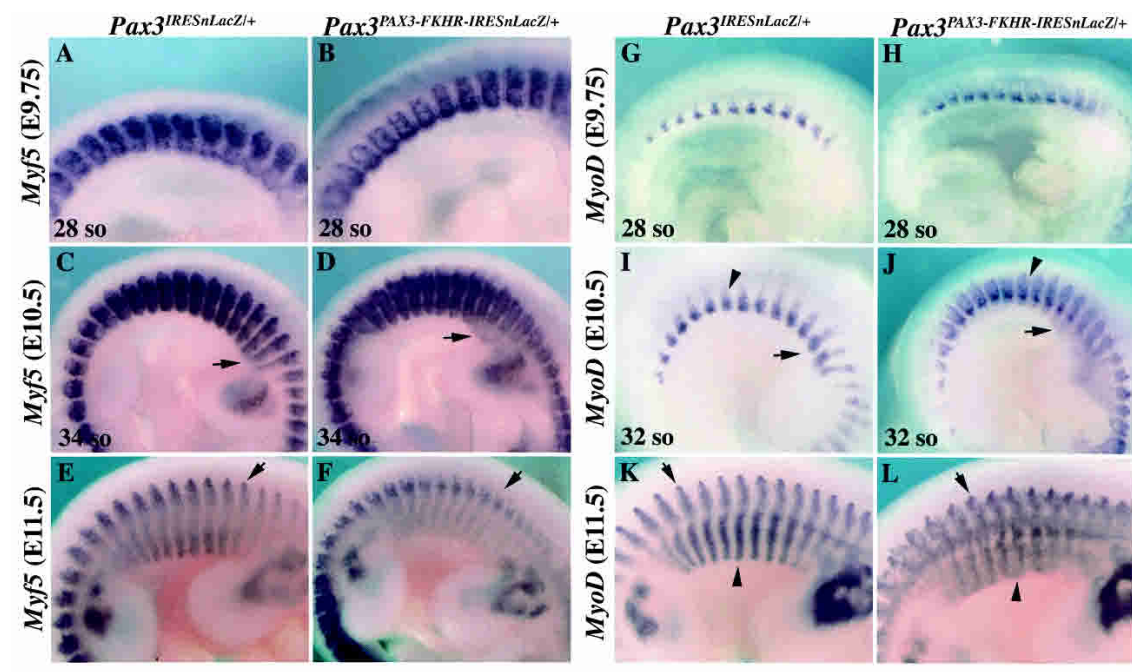

E10.5 Pax $3^{\text {IRESnLacZi+ }}(32$ so $)$
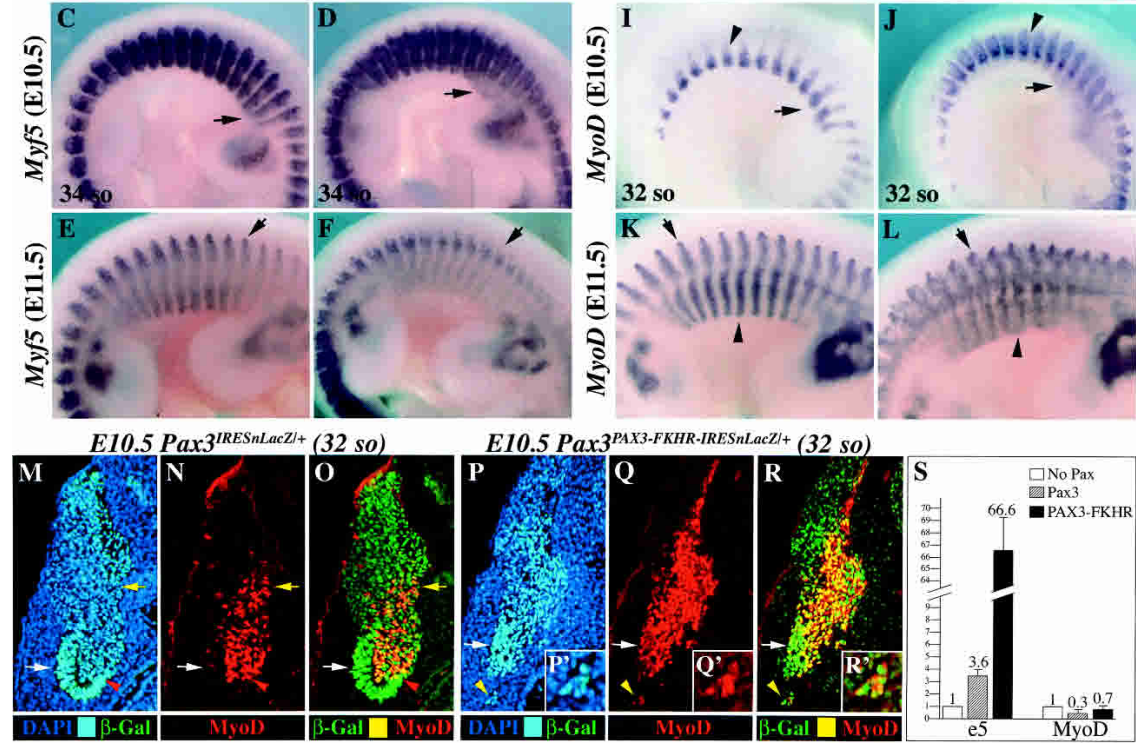

Figure 7. PAX3-FKHR leads to overexpression of $M y o D$ but not Myf5 in thoracic somites. $(A-F)$ In situ hybridization using an Myf5 probe on $\mathrm{Pax}^{\text {IRESnLacZ/+ }}$ embryos at $(A)$ E9.75, $(C)$ E10.5, and $(E)$ E11.5 and Pax3 ${ }^{\text {PAX3-FKHR-IRESnLacZ/+ embryos at }(B)}$ E9.75, $(D)$ E10.5, and $(F)$ E11.5 show similar levels of Myf5 transcripts in the somites. Ectopic migration of Myf5-positive cells to the forelimb is seen at E10.5 $(D$, black arrow; cf. $C)$, and at E11.5 the epaxial somite is disorganized in Pax3 ${ }^{\text {PAX3-FKHR-IRESnLacZ } /+}$ embryos $(F$, black arrow; cf. E). Somite numbers are indicated. $(G-L)$ In situ hybridization using an MyoD probe on Pax $^{\text {IRESnLacZ/+ }} \mathrm{em}$ bryos at $(G)$ E9.75, $(I)$ E10.5, and $(K)$ E11.5 and Pax $3^{\text {PAX3-FKHR-IRESnLacZ/+ }}$ embryos at $(H)$ E9.75, $(J)$ E10.5, and $(L)$ E11.5. The onset of $M y o D$ transcription is not perturbed $(G, H)$, but by E10.5, the MyoD expression domain is much more extensive in PaX3 ${ }^{\text {PAX3-FKHR-IRESnLacZ/+ }}$ (J, black arrowhead) compared with $\operatorname{Pax}^{\text {IRESnLacZ/+ }}$ control (I) embryos. MyoD transcripts are seen in cells adjacent to the somites and in the forelimb in Pax3 ${ }^{\text {PAX3-FKHR-IRESnLacZ/+ }}$ embryos at E10.5 (J, black arrow; cf. I). At E11.5, MyoD expression can be observed outside the myotomes of thoracic somitesin $\operatorname{Pax}^{\text {PAX3-FKHR-IRESnLacZ } /+}$ embryos $(L$, epaxial, arrow; hypaxial, arrowhead). (M-R) Coimmunohistochemistry with DAPI staining $(M, P)$, using MyoD antibody $(N, O, Q, R$, red) and $\beta$-Gal antibody $(N, O, Q, R$, green) on transverse sections of thoracic somites of Pax $3^{I R E S n L a c Z /+}(M-O)$ and Pax3 ${ }^{\text {PAX3-FKHR-IRESnLacZ/+ }}(P-R)$ embryos at E10.5. In Pax $3^{I R E S n L a c Z /+}$ embryos, $\beta-\mathrm{Gal}^{+}$cells are present in the epithelium of the hypaxial dermomyotome $(M-O$, white arrow) and in the

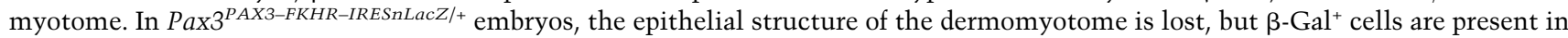
this region where again a few MyoD-positive cells are detected $\left(P-R\right.$, white arrow). Notably, $\beta$-Gal ${ }^{+}$cells are present throughout the whole myotome $(P)$, and most of these cells are MyoD-positive $(Q, R)$. Furthermore, cells that have migrated away from the somite $\left(P-R\right.$, yellow arrowhead) are $\beta-\mathrm{Gal}^{+}$, and coexpress MyoD (insets $\left.P^{\prime}-R^{\prime}\right)$. $(S)$ Transactivation of the $M y o D$ embryonic enhancer by Pax3 and PAX3-FKHR in 293 cells. For this, $1 \mu \mathrm{g}$ of test construct (or empty vector) was cotransfected with $0.2 \mu \mathrm{g}$ of $M y o D-T K-n L a c Z$ $(\mathrm{MyoD})$ or $(e 5)_{x 5}-T K-n L a c Z(\mathrm{e} 5)$ as a control, with $1 \mu \mathrm{g}$ of RSV-Luciferase for normalization. The data show the relative $\beta$-Gal activity $36 \mathrm{~h}$ after transfection. Fold induction was calculated as that over the activity measured in cells transfected with the expression vector alone. Mean values are given and the standard deviation is indicated for three independent determinations.

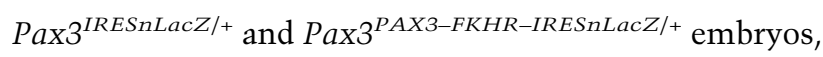
treated by coimmunohistochemistry using antibodies recognizing MyoD (red) and $\beta$-Gal (green), confirm that in the control embryos, MyoD is present in cells of the hypaxial myotome (Fig. 7M-O, yellow arrow; cf. Fig. 3L). Activation of $M y o D$ occurs in the epithelium of the hypaxial dermomyotome (Fig. 7M-O, white arrow; cf. Fig. $3 \mathrm{~L})$, where a few cells show colocalization of $\beta$-Gal (green) and MyoD (red). In Pax3 ${ }^{\text {PAX3-FKHR-IRESnLacZ/+ }}$ embryos, MyoD is present much more extensively throughout the myotome. The epithelial structure of the hypaxial dermomyotome is lost, but $\beta-\mathrm{Gal}^{+}$cells expressing MyoD are present in the putative dermomyotome (Fig. 7P-R, white arrow), and also ectopically where they have migrated from the somite (Fig. 7P-R, yellow arrowheads; $\left.7 \mathrm{P}^{\prime}, 7 \mathrm{Q}^{\prime}, 7 \mathrm{R}^{\prime}\right)$, in keeping with the interpretation of Figure 5, D and F. In more anterior somites, in the cervical region, $M y o D$ is already overexpressed at E10, in the presence of PAX3-FKHR (Fig. 5F). Later, at E11.5, ectopically located MyoD-expressing cells are present along the extent of the somite (Fig.
$7 \mathrm{~K}, \mathrm{~L})$. Although disorganization with characteristic bifurcations of the epaxial somite is also seen with an Myf5 probe at this stage, cell dispersion is not evident (Fig. 7E,F). This would suggest that MyoD but not Myf5 is activated by PAX3-FKHR in cells that have delaminated because of abnormal activation of c-met, consistent with the suggestion that $M y o D$, like c-met, is a target of Pax3. Such mispositioned cells do not receive the signals that lead to Myf5 activation, but once they have activated, $M y o D$ cells go on to express differentiated muscle markers (Fig. 4D), contributing to the disorganization of the trunk muscles provoked by PAX3-FKHR.

To determine whether the activation of $M y o D$ by Pax3 or PAX3-FKHR is direct or indirect, we isolated the $M y o D$ distal enhancer, which is able, when linked to an LacZ reporter gene, to recapitulate complete embryonic expression of $M y o D$ in transgenic mice (Goldhamer et al. 1992). Using transient transfections, we found that neither Pax3 nor PAX3-FKHR is able to activate the distal $M y o D$ enhancer (Fig. 7S). These data thus imply that Pax3/PAX3-FKHR activation of $M y o D$ is indirect. This 
is in contrast to the c-met promoter, which is activated by Pax3/PAX3-FKHR in vitro (Epstein et al. 1996).

\section{Discussion}

The gain-of-function allele, obtained by targeting Pax3 with the PAX3-FKHR sequence, saves the Pax3 mutant (Splotch) phenotype. The C-terminal sequence of FKHR, present in the fusion protein, contains a potent transcriptional activation domain, and PAX3-FKHR has been shown to act as an efficient transactivator on Pax3-binding sites in vitro (Bennicelli et al. 1999). This, therefore, strongly suggests that Pax3 acts by transcriptional activation in vivo, and points to the importance of putative coactivators. Because the only cofactors isolated to date act as corepressors and because HIRA (Magnaghi et al. 1998), Daxx (Hollenbach et al. 1999), and Rb (retinablastoma protein; Wiggan et al. 1998) interact with the homeodomain of Pax3, present in PAX3-FKHR to ensure DNA binding, it is formally possible that PAX3-FKHR can exert repressor activity. However, PAX3-FKHR appears to be completely unresponsive to Daxx corepression (Hollenbach et al. 1999), and the C-terminal transactivation domain of PAX3-FKHR is not sensitive to the inhibitory effects of the N-terminal PAX3 domain (Bennicelli et al. 1996; Bennicelli et al. 1999). All spontaneously occurring Splotch alleles lack the homeodomain (Tremblay and Gruss 1994), but mutations in other Pax genes such as the Sey ${ }^{N e u}$ mutation in Pax6 conserve this domain and lead to a loss-of-function phenotype similar to Sey, where the homeodomain is absent (Hill et al. 1991). The nlacZ reporter gene, preceded by multimerized Pax3-binding sites, revealed Pax transcriptional activation at many sites where Pax genes are expressed in the embryo, including the eye, pharyngeal regions, midbrain-hindbrain boundary region (data not shown) and notably in the somites, in myogenic precursor cells, and in neural crest derivatives such as the dorsal root ganglia, where Pax3 is functional. We therefore conclude that the Pax3 homeodomain and also the 5'-octamer sequence known to be important for Pax5 function (Eberhard et al. 2000), present in the PAX3-FKHR sequence, do not mediate major transcriptional repression at these sites in vivo. The rescue of the Pax3 mutant phenotype by PAX3-FKHR is therefore principally due to its function as a transcriptional activator.

It has been shown that overexpression of Pax3 can both activate and repress target genes (Khan et al. 1999; Mayanil et al. 2001). However, these experiments were performed ex vivo by overexpression of Pax3 and/or PAX3-FKHR in cell lines. Our genetic manipulation, in which the PAX3-FKHR transcriptional activator rescues the Pax3 mutant phenotype, provides an in vivo demonstration that Pax3 is acting as a transcriptional activator in somitogenesis and myogenesis, dorsal neural tube closure, and neural crest cell migration. However, this does not exclude the possibility that Pax 3 may act as a regulated transcription factor and also repress some target genes in vivo. Indeed, appearance of c-met transcripts in the dorsal neural tube in the presence of PAX3-FKHR may indicate that Pax3 normally represses c-met expression at this site. Furthermore, Pax3 has been reported to repress $M s x 2$ expression in the dorsal neural tube via a direct effect on a Pax3-binding site in the $M s x 2$ promoter and furthermore in $M s \times 2^{-/-} / \mathrm{Pax}^{\mathrm{Sp} / \mathrm{Sp}}$ double-mutant mice, the cardiac neural crest phenotype seen in the absence of Pax3 is rescued (Kwang et al. 2002). In previous experiments in which PAX3-FKHR was manipulated in vivo, fewer migrating neural crest cells were observed (Anderson et al. 2001), and mice had cardiac defects, probably as a result of neural crest perturbations (Lagutina et al. 2002). This may have been caused by interference with a repressor function of Pax3; however, it is striking that the $P a \times 3^{P A X 3-F K H R-I R E S-n l a c Z}$ allele that we describe restores neural crest migration in the Pax3 mutant background. The previous Pax3-FKHR allele showed a low level of expression, perhaps owing to the presence of the $P g k-N e o$ cassette (Lagutina et al. 2002).

Our analysis of the Pax $3^{P A X 3-F K H R-I R E S n L a c Z /+}$ phenotype focuses on myogenesis. Although expression of PAX3-FKHR, in the absence of Pax3, rescues the skeletal muscle phenotype of Splotch mutants, it also results in anomalies that illustrate the activator function of Pax3 and demonstrate that both $M y o D$ and c-met are targets. Interestingly, c-met is strongly expressed in the dorsal neural tube of embryos expressing PAX3-FKHR, but not in the control embryos (Fig. 6A,B). However c-met is not induced at other sites of $P a x 3$ expression, such as in the fronto-nasal processes or neural crest cells, suggesting that $\mathrm{Pax} 3$ activation of $\mathrm{c}-\mathrm{met}$ is also regulated by tissuespecific factors. Activation of $M y o D$ expression is limited to sites of myogenesis, and PAX3-FKHR does not lead to $M y o D$ transcription in nonmesodermal derivatives such as the neural tube or facial processes (Fig. 7). It had been shown previously that PAX3-FKHR is able to bind and directly transactivate the c-met promoter in vitro (Epstein et al. 1996). In contrast, in similar transactivation experiments in cultured cells, we show here that PAX3-FKHR activation of $M y o D$ is indirect (Fig. 7S). The Six homeoproteins are potential intermediaries (Relaix and Buckingham 1999), and it is notable that Six1, expressed in myogenic precursors, was found to be up-regulated by PAX3-FKHR in cultured cells (Khan et al. 1999). Six1 or Six4 is expressed within the muscle lineage in a wider domain than $P a x 3$, which prevented analysis of ectopic activation of these genes in Pax3 ${ }^{\text {PAX3-FKHR-IRESnLacZ/+ }}$ embryos (data not shown; see Ozaki et al. 2001; Laclef et al. 2003a,b). However, we did not find evidence for up-regulation of Eya1 or Eya2, which encode Six cofactors and are part of the regulatory

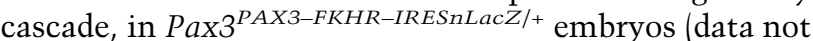
shown). This suggests that the relationship between Pax3 and the Six/Eya/Dach genetic cascade may be more complex than previously proposed. Analysis of Myf5 and Splotch single and double mutants showed genetically that either Myf5 or Pax3 is required for activation of $M y o D$ and subsequent myogenesis in the trunk and limbs (Tajbakhsh et al. 1997). This loss-of-function study is now complemented by the gain-of-function analysis reported here, which shows that PAX3-FKHR leads to 
overactivation of $M y o D$, while having no effect on $M y f 5$, which is in a parallel genetic pathway. Thus transcriptional activation by $\mathrm{Pax} 3$, although indirect, is sufficient for $M y o D$ expression in vivo. This is in keeping with the observation that ectopic expression of Pax3 in chick embryo explants results in $M y o D$ activation (Maroto et al. 1997). However, in these experiments Myf5 was also activated by Pax3. Ectopic overexpression of Pax3, followed by $5 \mathrm{~d}$ of culture, may have led to perturbations in other components of the explants, which then affect Myf5 activation, possibly implying that the myogenic regulatory cascade differs between birds and mammals.

Overexpression of c-met has the most dramatic consequences in the interlimb region, where the gene is normally expressed in the hypaxial dermomyotome, but where, in the absence of the ligand, HGF/SF, Met signaling is not activated. The introduction of beads coated with HGF/SF leads to delamination and migration of c-met-expressing cells from thoracic somites of chicken embryos (Brand-Saberi et al. 1996; Heymann et al. 1996), and indeed, with Fgf, can result in ectopic limb formation (Cohn et al. 1995). Overexpression of c-met in the presence of PAX3-FKHR is not accompanied by any change in HGF/SF expression, but nevertheless results in ectopic delamination of cells from somites in the interlimb region. The role of c-met in this phenomenon is confirmed, genetically, by the abrogation of the delamination phenotype as the number of c-met alleles is reduced. We show that the Met receptor is present as a phosphorylated form, which is diagnostic of activated Met signaling. Such ligand-independent Met dimerization has been observed previously in tumors that express high levels of Met (Bergstrom et al. 1999). The fact that this can occur in vivo points to the importance of controlling the extent of c-met activation during development. The PAX3-FKHR result indicates that Pax3 is a key regulator of c-met in the somite. The activation of Met signaling is probably one of the reasons that the PAX3/FKHR translocation leads to rhabdomyosarcomas. It has been shown that c-met is expressed in ARMS with the $\mathrm{t}(2 ; 13)$ translocation (Epstein et al. 1996; Ginsberg et al. 1998), and the implication of the Met pathway in rhabdomyosarcomas is also suggested by a recent report that showed that aberrant expression of $\mathrm{HGF} / \mathrm{SF}$ results in an embryonal variant of rhabdomyosarcoma in mice with a deletion in the tumor suppressor locus Ink4a/Arf (Sharp et al. 2002). Mice with the Pax $3^{P A X 3-F K H R-I R E S n l a c Z}$ allele die at birth, and show no signs of tumors. It remains to be seen whether activation of this conditional allele postnatally will result in ARMS or whether tumor formation depends on a second mutation in a tumorsuppressor gene.

The Alveolar subtype of RMS is much more metastatic than its embryonal RMS counterpart (ERMS), which does not express PAX3-FKHR. This metastatic behavior is the main reason that ARMS is much more malignant than ERMS. The ability of Met to enhance cell dissociation, motility, and survival is probably important in neoplastic invasion and migration to metastatic sites of many tumors (Birchmeier et al. 1997; Tru- solino and Comoglio 2002). Our results in the embryo show a role for ligand-independent Met signaling that may be a critical pathological factor in PAX3-FKHR-associated metastasis.

Perinatal death of $\operatorname{Pax}^{P A X 3-F K H R-I R E S n l a c Z+}$ fetuses is probably caused by respiratory failure because of the rib phenotype. This is also seen with mice mutated for the myogenic factor genes Myf5 (Braun et al. 1992; Tajbakhsh et al. 1996) and Myogenin (Vivian et al. 1999, 2000), where it is a secondary consequence of perturbations in skeletal muscle formation. Precisely why distal rib development is affected is not clear. It may be because of the disorganization of later muscle masses in the trunk, which is also seen in the presence of PAX3-FKHR or, indeed, in the absence of Pax3; Splotch mice also have a rib phenotype (Henderson et al. 1999). However, in Myf5 mutant mice, the early myotome does not form, and it has been proposed that this affects the underlying sclerotome from which the ribs derive (Braun et al. 1992; Huang et al. 2000). In the case of Pax3 loss- or gain-offunction mutants, the myotome is present, but compromised hypaxially as a result of loss of the hypaxial dermomyotome, limiting affects on the sclerotome to this location. Indeed, it has been shown recently that this is the site of distal rib formation, which takes place in close proximity to the hypaxial (dermo)myotome in conjunction with the formation of intercostal muscles (Evans 2003).

Trunk muscles remain disorganized at later developmental stages in Pax3 ${ }^{P A X 3-F K H R-I R E S n l a c Z+}$ embryos, whereas those in the cervical region and limbs that are also subject to overexpression of c-met recover, suggesting differential regulation of muscle growth and patterning between these and the thoracic region. In the case of the limbs, there is ectopic recruitment of myogenic cells that are already expressing Myf5 and MyoD. Normally these genes are only activated once somitic cells reach the limb buds (Sassoon et al. 1989; Tajbakhsh and Buckingham 1994). This is in contrast to myogenic cells of the hypoglossal cord, for example. However, these cells move as a coherent mass, rather than as the loosely migrating mesenchymal cells seen at limb level. Apparently, the presence of myogenic determination factors and hence the initiation of the myogenic program does not prevent Met/HGF-mediated migration to the limb bud. Overexpression of $M y o D$, which is very evident in cervical as well as thoracic somites, does not appear to have deleterious consequences in the long term. In the thoracic region, ectopic activation of $M y o D$ due to PAX3-FKHR in cells that delaminate abnormally because of an excess of Met, leads to muscle cell differentiation. Notably this takes place in the absence of Myf5, which is not affected by PAX3-FKHR.

Perturbations in somitogenesis have an indirect effect on myogenic progenitor cells, whether they subsequently activate $M y f 5$ or MyoD. In the absence of Pax3, the epithelial dermomyotome is severely affected with reduction and abnormal bifurcations of the epaxial extremity and loss of the hypaxial part. The central dermomyotome is probably less affected because of $\operatorname{Pax} 7$ ex- 
pression (F. Relaix and M. Buckingham, in prep.). In addition to its role, through c-met activation, in the epithelial/mesenchymal transition exemplified by the delamination of myogenic progenitor cells, Pax3 also promotes epithelialization. This has been documented in mesenchymal mammalian cell lines, in which expression of Pax3 induced cytoskeletal changes and increased cell adhesion, accompanied by changes in cell size and shape (Wiggan et al. 2002). Mild perturbations of somite structure, for example, epaxial bifurcations revealed after Myf5 in situ hybridization (Fig. 7F), may reflect minor deregulation of somite epithelialization in the presence of PAX3-FKHR, independent of later effects due to ectopic delamination of c-met-expressing cells. In a Pax3null background, PAX3-FKHR corrects the loss of the hypaxial dermomyotome. It is clear that Met, which can also play a role in cell proliferation/survival, is not implicated in this aspect of the Splotch phenotype, because in c-met mutant mice the epithelial dermomyotome is unaffected. It is probable that the apoptosis documented in Splotch mutants (Borycki et al. 1999) is avoided by activation of antiapoptotic genes targeted by Pax3/ PAX3-FKHR, in addition to genes involved in epithelialization. A p53 loss-of-function mutation rescues apoptosis and neural tube defects in the Splotch mutant (Pani et al. 2002), pointing to the role of $\operatorname{Pax} 3$ as an inhibitor of p53-dependent apoptosis.

In conclusion, PAX3-FKHR can replace Pax3 in the transcriptional activation of a number of key genes involved in somitogenesis and myogenesis. Among these, c-met and $M y o D$ are shown to be targets of this gain-offunction allele. Their overactivation has interesting implications for Met functioning and for the onset of myogenesis. Furthermore, overactivation of Pax3 pathways in a myogenic context probably underlies the formation of human rhabdomyosarcoma that results from the PAX3/FKHR translocation.

\section{Materials and methods}

\section{Targeting vectors and mice}

To target the Pax3 locus, we isolated a 10-kb ClaI fragment containing $6 \mathrm{~kb}$ of the $5^{\prime}$ region and exons 1-4 of $P a x 3$, from a bank of 129/sv mouse DNA selected for 9-11-kb size fragments after digestion with ClaI. This fragment was then used to generate a $P a \times 3^{\text {IRESnLacZ }}$ targeting vector containing $3 \mathrm{~kb}$ of genomic sequence (in part by PCR, followed by sequencing), $5^{\prime}$ to the Pax3 gene in which an IRESnLacZpA reporter cassette replaces exon 2 (which contains the start of the paired domain) followed by a floxed PGK-Puromycin-poly $(A)$ selection cassette and $3 \mathrm{~kb}$ of genomic sequence extending to the ClaI site in exon 4. The poly(A) sequence used in these cassettes was that of the bovine growth hormone mRNA (Meilhac et al. 2003). The $P a \times 3^{\text {PAX3-FKHR-IRESnLACZ }}$ targeting vector contained $2.4 \mathrm{~kb}$ of $5^{\prime}$ genomic region, replacing the coding sequence of exon 1 , up to the BamHI site, $20 \mathrm{bp} \mathrm{3'}$ of the splice donor site of exon 1 , to remove any possibility of translational reinitiation, and $4 \mathrm{~kb}$ of 3 ' sequence containing exons $2-4$. In addition, a PGK-DTA cassette encoding the A subunit of the Diphtheria Toxin gene (Meilhac et al. 2003) was inserted $5^{\prime}$ of the constructs to allow for negative selection in ES cells. The Pax3 ${ }^{\text {IRESnLacZ }}$ targeting vector was electroporated into HMI ES cells according to Meilhac et al. (2003), and the Pax3 ${ }^{\text {PAX3-FKHR-IRESnLACZ }}$ targeting vector was electroporated into CK35 ES cells (Kress et al. 1998). ES cells were selected and screened for recombination events by Southern blot analysis using EcoRV digests and a 5 '-flanking probe (Fig. 1). Targeted ES cells were recovered with a $0.5 \%-1 \%$ frequency and injected into blastocysts to generate chimaeras. Germ-line-transmitted alleles were identified by the classical Splotch heterozygote phenotype (lack of melanocyte colonization of the bellyl, and by PCR or Southern blotting.

c-met mutant mice were genotyped by PCR according to published conditions (Maina et al. 1996). Pax3 ${ }^{\text {PAX3-FKHR-IRESnLacZ/ }}$ c-met ${ }^{D}$ compound mutants were generated by crossing Pax3 $3^{\text {(Puro)PAX3-FKHR-IRESnLacZ/+ }} / \mathrm{c}-\mathrm{met}^{D /+}$ males with PGK-Cre/c-met ${ }^{D /+}$ (Lallemand et al. 1998) females, and

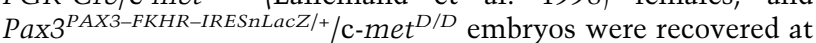
the expected frequency of $1 / 8$. Pax $3^{\text {PAX3-FKHR-IRESnLacZ/Splotch }}$ compound mutants were generated by crossing Pax3 ${ }^{\text {(Puro)PAX3-FKHR-IRESnLacZ/+ }}$ males with PGK-Cre/Splotch (Lallemand et al. 1998) females, and Pax3 ${ }^{\text {PAX3-FKHR-IRESnLacZ/Sp }}$ embryos were recovered at the expected frequency of $1 / 4$ (PGKCre is maternally expressed and therefore does not require germ-line transmission to be functional).

X-Gal staining, histology, immunohistochemistry, whole-mount in situ hybridization, and whole-mount immunohistochemistry

We collected mouse embryos after natural overnight matings; for staging, fertilization was considered to take place at 6 a.m. For X-Gal staining, dissected embryos were fixed for 10-30 min (depending on the stage) with $4 \%$ paraformaldehyde (PAF) in PBS, on ice. Embryos were rinsed twice with PBS, then stained with X-Gal (Roche), using $0.4 \mathrm{mg} / \mathrm{mL} \mathrm{X-Gal} \mathrm{in} 2 \mathrm{mM} \mathrm{MgCl}_{2}$, $0.02 \% \mathrm{NP}-40,0.1 \mathrm{M}$ PBS (pH 7.5), $20 \mathrm{mM} \mathrm{K}_{4} \mathrm{Fe}(\mathrm{CN})_{6}$, and 20 $\mathrm{mM} \mathrm{K}_{3} \mathrm{Fe}(\mathrm{CN})_{6}$ at $37^{\circ} \mathrm{C}$ for $4-16 \mathrm{~h}$, with shaking. Embryos were rinsed in PBS and postfixed overnight in $4 \%$ PAF. For histological analysis, sections $(12 \mu \mathrm{m})$ were prepared from X-Gal-colored embryos and stained with eosin according to standard procedures. Genotyping for whole-mount in situ hybridization was carried out by X-Gal staining in X-Gal $+0.2 \%$ PAF for $30 \mathrm{~min}$ following $1-2 \mathrm{~h}$ fixation in $4 \% \mathrm{PAF}$, on ice. When light color had developed, embryos were rinsed in PBS and postfixed overnight in $4 \%$ PAF. Whole-mount in situ hybridization with digoxigenin-labeled riboprobes was performed as described (Tajbakhsh et al. 1997). MyoD and Myf5 riboprobes have been previously described (Tajbakhsh et al. 1997). The c-met probe was kindly provided by C. Birchmeier (Bladt et al. 1995), and the Pax3 probe was kindly provided by P. Gruss. Fluorescent coimmunohistochemistry was done according to Daubas et al. (2000), using the following antibodies: polyclonal anti- $\beta-G a l$ (Molecular Probe; diluted 1:200), polyclonal anti-Laminin (Sigma; 1:200), monoclonal anti- $\beta-G a l$ (Sigma; 1:200), monoclonal anti-MyoD (DAKO; 1:200), monoclonal anti-Phospho-Met (Tyr 1234/1235, Cell Signaling; 1:50). Whole-mount immunohistochemistry was done according to Guris et al. (2001), using a mouse monoclonal anti-troponin $\mathrm{T}$ antibody (Sigma; $1: 200)$ and a mouse monoclonal anti-desmin antibody (DAKO; 1:200). Alizarin redAlcian blue staining of bone and cartilage was done according to Braun et al. (1992).

\section{Generation of transgenic embryos}

To generate Pax3 reporter embryos, oligonucleotides containing the Pax3 consensus binding site defined by Epstein et al. (1996) were multimerized. The sequence of the oligonucleotides is as 
follows: CSSPax3-A, 5'-CCTCGTCACGCTTCGAATGT-3'; and CSSPax3-B, 5'-GGGACATTCGAAGCGTGACGA-3'. The oligonucleotides were annealed and polymerized. Concatemeres containing five binding sites were gel-purified, and cloned into a $T K-n L a c Z p A$ vector, which contains the nlacZ reporter gene under the control of the thymidine kinase (TK) promoter (Hadchouel et al. 2003), into an SfiI site located $5^{\prime}$ to the TK minimal promoter. A 7.4-kb plasmid fragment for injection was isolated using XhoI and NotI as described previously (Kelly et al. 1995). Transgenic mice were generated as previously described (Hadchouel et al. 2003). Embryos were harvested at E10.5 and X-Gal-stained.

\section{Transient transfection experiments}

The MyoD-TK-nLacZ reporter was described previously (Primig et al. 1998). For $(e 5)_{x 5}-T K-n l a c Z$, oligonucleotides containing the Pax3-binding site found in the MITF promoter (ccettgtctat TAATactactGGACtaaaga) were annealed and polymerized five times in front of the TK-nLacZ reporter construct. Transient transfections, $\beta$-galactosidase, and Luciferase assays were performed as described (Primig et al. 1998).

\section{Acknowledgments}

We thank Catherine Bodin and Dominique Michel for technical assistance, and the Buckingham lab for helpful discussions. The work in M.B.'s laboratory was supported by the Pasteur Institute, the CNRS, and by grants from the AFM, the AC Integrative Biology program of the M.J.E.R., and a Galileo program grant from the French Foreign Ministry to M.B. and M.R.P. Grants from the Swiss National Science Foundation (grant No. 31-67841.02) to B.W.S. and Telethon Italy to C.P., as well as the continuing support of the Compagnia di San Paolo and Fondazione CRT to C.P.'s laboratory, are gratefully acknowledged. F.R. is supported by Inserm. M.R.P. benefited from fellowships from the Cenci-Bolognetti Foundation and the AFM.

The publication costs of this article were defrayed in part by payment of page charges. This article must therefore be hereby marked "advertisement" in accordance with 18 USC section 1734 solely to indicate this fact.

\section{References}

Anderson, M.J., Shelton, G.D., Cavenee, W.K., and Arden, K.C. 2001. Embryonic expression of the tumor-associated PAX3FKHR fusion protein interferes with the developmental functions of Pax3. Proc. Nat1. Acad. Sci. 98: 1589-1594.

Auerbach, R. 1954. Analysis of the developmental effects of a lethal mutation in the house mouse. J. Exper. Zool. 127: 305-329.

Barr, F.G. 2001. Gene fusions involving PAX and FOX family members in alveolar rhabdomyosarcoma. Oncogene 20: 5736-5746.

Bennicelli, J.L., Edwards, R.H., and Barr, F.G. 1996. Mechanism for transcriptional gain of function resulting from chromosomal translocation in alveolar rhabdomyosarcoma. Proc. Natl. Acad. Sci. 93: 5455-5459.

Bennicelli, J.L., Advani, S., Schafer, B.W., and Barr, F.G. 1999. PAX3 and PAX7 exhibit conserved cis-acting transcription repression domains and utilize a common gain of function mechanism in alveolar rhabdomyosarcoma. Oncogene 18: 4348-4356.

Bergstrom, J.D., Hermansson, A., Diaz de Stahl, T., and Heldin, N.E. 1999. Non-autocrine, constitutive activation of Met in human anaplastic thyroid carcinoma cells in culture. Br. J. Cancer 80: 650-656.

Birchmeier, W., Brinkmann, V., Niemann, C., Meiners, S., DiCesare, S., Naundorf, H., and Sachs, M. 1997. Role of HGF/SF and c-Met in morphogenesis and metastasis of epithelial cells. Ciba Found. Symp. 212: 230-246.

Bladt, F., Riethmacher, D., Isenmann, S., Aguzzi, A., and Birchmeier, C. 1995. Essential role for the c-met receptor in the migration of myogenic precursor cells into the limb bud. Nature 376: 768-771.

Bober, E., Franz, T., Arnold, H.H., Gruss, P., and Tremblay, P. 1994. Pax-3 is required for the development of limb muscles: A possible role for the migration of dermomyotomal muscle progenitor cells. Development 120: 603-612.

Borycki, A.G., Li, J., Jin, F., Emerson, C.P., and Epstein, J.A. 1999. Pax3 functions in cell survival and in pax7 regulation. Development 126: 1665-1674.

Brand-Saberi, B., Muller, T.S., Wilting, J., Christ, B., and Birchmeier, C. 1996. Scatter factor/hepatocyte growth factor (SF/ HGF) induces emigration of myogenic cells at interlimb level in vivo. Dev. Biol. 179: 303-308.

Braun, T., Rudnicki, M.A., Arnold, H.H., and Jaenisch, R. 1992. Targeted inactivation of the muscle regulatory gene Myf-5 results in abnormal rib development and perinatal death. Cell 71: 369-382.

Cohn, M.J., Izpisua-Belmonte, J.C., Abud, H., Heath, J.K., and Tickle, C. 1995. Fibroblast growth factors induce additional limb development from the flank of chick embryos. Cell 80: 739-746.

Czerny, T., Schaffner, G., and Busslinger, M. 1993. DNA sequence recognition by Pax proteins: Bipartite structure of the paired domain and its binding site. Genes \& Dev. 7: 2048-2061.

Dahl, E., Koseki, H., and Balling, R. 1997. Pax genes and organogenesis. Bioessays 19: 755-765.

Daubas, P., Tajbakhsh, S., Hadchouel, J., Primig, M., and Buckingham, M. 2000. Myf5 is a novel early axonal marker in the mouse brain and is subjected to post-transcriptional regulation in neurons. Development 127: 319-331.

Dietrich, S., Abou-Rebyeh, F., Brohmann, H., Bladt, F., Sonnenberg-Riethmacher, E., Yamaai, T., Lumsden, A., Brand-Saberi, B., and Birchmeier, C. 1999. The role of SF/HGF and c-Met in the development of skeletal muscle. Development 126: 1621-1629.

Eberhard, D., Jimenez, G., Heavey, B., and Busslinger, M. 2000. Transcriptional repression by Pax5 (BSAP) through interaction with corepressors of the Groucho family. EMBO $J$. 19: 2292-2303.

Epstein, J.A., Shapiro, D.N., Cheng, J., Lam, P.Y., and Maas, R.L. 1996. Pax3 modulates expression of the c-Met receptor during limb muscle development. Proc. Natl. Acad. Sci. 93: 42134218.

Evans, D.J. 2003. Contribution of somitic cells to the avian ribs. Dev. Biol. 256: 114-126.

Franz, T., Kothary, R., Surani, M.A., Halata, Z., and Grim, M. 1993. The Splotch mutation interferes with muscle development in the limbs. Anat. Embryol. (Berl) 187: 153-160.

Galibert, M.D., Yavuzer, U., Dexter, T.J., and Goding, C.R. 1999. Pax3 and regulation of the melanocyte-specific tyrosinase-related protein-1 promoter. J. Biol. Chem. 274: 26894-26900.

Ginsberg, J.P., Davis, R.J., Bennicelli, J.L., Nauta, L.E., and Barr, F.G. 1998. Up-regulation of MET but not neural cell adhesion molecule expression by the PAX3-FKHR fusion protein in alveolar rhabdomyosarcoma. Cancer Res. 58: 3542-3546.

Goldhamer, D.J., Faerman, A., Shani, M., and Emerson Jr., C.P. 1992. Regulatory elements that control the lineage-specific expression of myoD. Science 256: 538-542. 
Goulding, M., Lumsden, A., and Paquette, A.J. 1994. Regulation of Pax-3 expression in the dermomyotome and its role in muscle development. Development 120: 957-971.

Guris, D.L., Fantes, J., Tara, D., Druker, B.J., and Imamoto, A. 2001. Mice lacking the homologue of the human 22q11.2 gene CRKL phenocopy neurocristopathies of DiGeorge syndrome. Nat. Genet. 27: 293-298.

Hadchouel, J., Tajbakhsh, S., Primig, M., Chang, T.H., Daubas, P., Rocancourt, D., and Buckingham, M. 2000. Modular long-range regulation of Myf5 reveals unexpected heterogeneity between skeletal muscles in the mouse embryo. Development 127: 4455-4467.

Hadchouel, J., Carvajal, J.J., Daubas, P., Bajard, L., Chang, T., Rocancourt, D., Cox, D., Summerbell, D., Tajbakhsh, S., Rigby, P.W., et al. 2003. Analysis of a key regulatory region upstream of the Myf5 gene reveals multiple phases of myogenesis, orchestrated at each site by a combination of elements dispersed throughout the locus. Development 130: 3415-3426.

Henderson, D.J., Conway, S.J., and Copp, A.J. 1999. Rib truncations and fusions in the $\mathrm{Sp} 2 \mathrm{H}$ mouse reveal a role for Pax3 in specification of the ventro-lateral and posterior parts of the somite. Dev. Biol. 209: 143-158.

Heymann, S., Koudrova, M., Arnold, H., Koster, M., and Braun, T. 1996. Regulation and function of SF/HGF during migration of limb muscle precursor cells in chicken. Dev. Biol. 180: $566-578$.

Hill, R.E., Favor, J., Hogan, B.L., Ton, C.C., Saunders, G.F., Hanson, I.M., Prosser, J., Jordan, T., Hastie, N.D., and van Heyningen, V. 1991. Mouse small eye results from mutations in a paired-like homeobox-containing gene. Nature 354: 522525 .

Hollenbach, A.D., Sublett, J.E., McPherson, C.J., and Grosveld, G. 1999. The Pax3-FKHR oncoprotein is unresponsive to the Pax3-associated repressor hDaxx. EMBO J. 18: 3702-3711.

Houzelstein, D., Auda-Boucher, G., Cheraud, Y., Rouaud, T., Blanc, I., Tajbakhsh, S., Buckingham, M.E., Fontaine-Perus, J., and Robert, B. 1999. The homeobox gene Msx1 is expressed in a subset of somites, and in muscle progenitor cells migrating into the forelimb. Development 126: 26892701.

Huang, R., Zhi, Q., Schmidt, C., Wilting, J., Brand-Saberi, B., and Christ, B. 2000. Sclerotomal origin of the ribs. Development 127: 527-532.

Jostes, B., Walther, C., and Gruss, P. 1990. The murine paired box gene, Pax7, is expressed specifically during the development of the nervous and muscular system. Mech. Dev. 33: $27-37$.

Kelly, R., Alonso, S., Tajbakhsh, S., Cossu, G., and Buckingham, M. 1995. Myosin light chain 3F regulatory sequences confer regionalized cardiac and skeletal muscle expression in transgenic mice. J. Cell Biol. 129: 383-396.

Khan, J., Bittner, M.L., Saal, L.H., Teichmann, U., Azorsa, D.O., Gooden, G.C., Pavan, W.J., Trent, J.M., and Meltzer, P.S. 1999. cDNA microarrays detect activation of a myogenic transcription program by the PAX3-FKHR fusion oncogene. Proc. Natl. Acad. Sci. 96: 13264-13269.

Kress, C., Vandormael-Pournin, S., Baldacci, P., Cohen-Tannoudji, M., and Babinet, C. 1998. Nonpermissiveness for mouse embryonic stem (ES) cell derivation circumvented by a single backcross to $129 / \mathrm{Sv}$ strain: Establishment of ES cell lines bearing the Omd conditional lethal mutation. Mamm. Genome 9: 998-1001.

Kwang, S.J., Brugger, S.M., Lazik, A., Merrill, A.E., Wu, L.Y., Liu, Y.H., Ishii, M., Sangiorgi, F.O., Rauchman, M., Sucov, H.M., et al. 2002. Msx2 is an immediate downstream effec- tor of Pax3 in the development of the murine cardiac neural crest. Development 129: 527-538.

Laclef, C., Hamard, G., Demignon, J., Souil, E., Houbron, C., and Maire, P. 2003a. Altered myogenesis in Six1-deficient mice. Development 130: 2239-2252.

Laclef, C., Souil, E., Demignon, J., and Maire, P. 2003b. Thymus, kidney and craniofacial abnormalities in Sixl deficient mice. Mech. Dev. 120: 669-679.

Lagutina, I., Conway, S.J., Sublett, J., and Grosveld, G.C. 2002. Pax3-FKHR knock-in mice show developmental aberrations but do not develop tumors. Mol. Cell. Biol. 22: 7204-7216.

Lallemand, Y., Luria, V., Haffner-Krausz, R., and Lonai, P. 1998. Maternally expressed PGK-Cre transgene as a tool for early and uniform activation of the Cre site-specific recombinase. Transgenic Res. 7: 105-112.

Longati, P., Bardelli, A., Ponzetto, C., Naldini, L., and Comoglio, P.M. 1994. Tyrosines1234-1235 are critical for activation of the tyrosine kinase encoded by the MET proto-oncogene (HGF receptor). Oncogene 9: 49-57.

Magnaghi, P., Roberts, C., Lorain, S., Lipinski, M., and Scambler, P.J. 1998. HIRA, a mammalian homologue of Saccharomyces cerevisiae transcriptional co-repressors, interacts with Pax3. Nat. Genet. 20: 74-77.

Maina, F., Casagranda, F., Audero, E., Simeone, A., Comoglio, P.M., Klein, R., and Ponzetto, C. 1996. Uncoupling of Grb2 from the Met receptor in vivo reveals complex roles in muscle development. Cell 87: 531-42.

Maroto, M., Reshef, R., Munsterberg, A.E., Koester, S., Goulding, M., and Lassar, A.B. 1997. Ectopic Pax-3 activates MyoD and Myf-5 expression in embryonic mesoderm and neural tissue. Cell 89: 139-148.

Mayanil, C.S., George, D., Freilich, L., Miljan, E.J., Mania-Farnell, B., McLone, D.G., and Bremer, E.G. 2001. Microarray analysis detects novel Pax3 downstream target genes. J. Biol. Chem. 276: 49299-49309.

Meilhac, S.M., Kelly, R.G., Rocancourt, D., Eloy-Trinquet, S., Nicolas, J.F., and Buckingham, M.E. 2003. A retrospective clonal analysis of the myocardium reveals two phases of clonal growth in the developing mouse heart. Development 130: 3877-3889.

Nutt, S.L., Eberhard, D., Horcher, M., Rolink, A.G., and Busslinger, M. 2001. Pax5 determines the identity of B cells from the beginning to the end of B-lymphopoiesis. Int. Rev. Immunol. 20: 65-82.

Ozaki, H., Watanabe, Y., Takahashi, K., Kitamura, K., Tanaka, A., Urase, K., Momoi, T., Sudo, K., Sakagami, J., Asano, M., et al. 2001. Six4, a putative myogenin gene regulator, is not essential for mouse embryonal development. Mol. Cell. Biol. 21: 3343-3350.

Pani, L., Horal, M., and Loeken, M.R. 2002. Rescue of neural tube defects in Pax-3-deficient embryos by p53 loss of function: Implications for Pax-3-dependent development and tumorigenesis. Genes \& Dev. 16: 676-680.

Primig, M., Chang, T.H., and Buckingham, M. 1998. A novel GFPneo vector designed for the isolation and analysis of enhancer elements in transfected mammalian cells. Gene 215: 181-189.

Relaix, F. and Buckingham, M. 1999. From insect eye to vertebrate muscle: Redeployment of a regulatory network. Genes \& Dev. 13: 3171-3178.

Rudnicki, M.A., Schnegelsberg, P.N., Stead, R.H., Braun, T., Arnold, H.H., and Jaenisch, R. 1993. MyoD or Myf-5 is required for the formation of skeletal muscle. Cell 75: 1351-1359.

Sassoon, D., Lyons, G., Wright, W.E., Lin, V., Lassar, A., Weintraub, H., and Buckingham, M. 1989. Expression of two myogenic regulatory factors myogenin and MyoD1 during mouse embryogenesis. Nature 341: 303-307. 
Sharp, R., Recio, J.A., Jhappan, C., Otsuka, T., Liu, S., Yu, Y., Liu, W., Anver, M., Navid, F., Helman, L.J., et al. 2002. Synergism between INK4a/ARF inactivation and aberrant HGF/ SF signaling in rhabdomyosarcomagenesis. Nat. Med. 8: 1276-1280.

Tajbakhsh, S. and Buckingham, M.E. 1994. Mouse limb muscle is determined in the absence of the earliest myogenic factor myf-5. Proc. Nat1. Acad. Sci. 91: 747-751.

. 2000. The birth of muscle progenitor cells in the mouse: Spatiotemporal considerations. Curr. Top. Dev. Biol. 48: 225-268.

Tajbakhsh, S., Bober, E., Babinet, C., Pournin, S., Arnold, H., and Buckingham, M. 1996. Gene targeting the myf-5 locus with nlacZ reveals expression of this myogenic factor in mature skeletal muscle fibres as well as early embryonic muscle. Dev. Dyn. 206: 291-300.

Tajbakhsh, S., Rocancourt, D., Cossu, G., and Buckingham, M. 1997. Redefining the genetic hierarchies controlling skeletal myogenesis: Pax-3 and Myf-5 act upstream of MyoD. Cell 89: $127-138$.

Thery, C., Sharpe, M.J., Batley, S.J., Stern, C.D., and Gherardi, E. 1995. Expression of HGF/SF, HGF1/MSP, and c-met suggests new functions during early chick development. Dev. Genet. 17: 90-101.

Tremblay, P. and Gruss, P. 1994. Pax: Genes for mice and men. Pharmacol. Ther. 61: 205-226.

Tremblay, P., Dietrich, S., Mericskay, M., Schubert, F.R., Li, Z., and Paulin, D. 1998. A crucial role for Pax3 in the development of the hypaxial musculature and the long-range migration of muscle precursors. Dev. Biol. 203: 49-61.

Trusolino, L. and Comoglio, P.M. 2002. Scatter-factor and semaphorin receptors: Cell signalling for invasive growth. Nat. Rev. Cancer 2: 289-300.

van Heyningen, V. and Williamson, K.A. 2002. PAX6 in sensory development. Hum. Mol. Genet. 11: 1161-1167.

Vivian, J.L., Gan, L., Olson, E.N., and Klein, W.H. 1999. A hypomorphic myogenin allele reveals distinct myogenin expression levels required for viability, skeletal muscle development, and sternum formation. Dev. Biol. 208: 44-55.

Vivian, J.L., Olson, E.N., and Klein, W.H. 2000. Thoracic skeletal defects in myogenin- and MRF4-deficient mice correlate with early defects in myotome and intercostal musculature. Dev. Biol. 224: 29-41.

Watanabe, A., Takeda, K., Ploplis, B., and Tachibana, M. 1998. Epistatic relationship between Waardenburg syndrome genes MITF and PAX3. Nat. Genet. 18: 283-286.

Wiggan, O., Taniguchi-Sidle, A., and Hamel, P.A. 1998. Interaction of the pRB-family proteins with factors containing paired-like homeodomains. Oncogene 16: 227-236.

Wiggan, O., Fadel, M.P., and Hamel, P.A. 2002. Pax3 induces cell aggregation and regulates phenotypic mesenchymal-epithelial interconversion. J. Cell Sci. 115: 517-529.

Yang, X.M., Vogan, K., Gros, P., and Park, M. 1996. Expression of the met receptor tyrosine kinase in muscle progenitor cells in somites and limbs is absent in Splotch mice. Development 122: 2163-2171. 


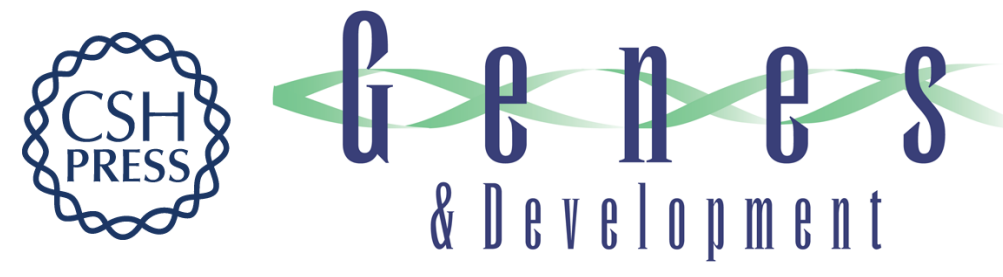

\section{The transcriptional activator PAX3-FKHR rescues the defects of Pax3 mutant mice but induces a myogenic gain-of-function phenotype with ligand-independent activation of Met signaling in vivo}

Frédéric Relaix, Mariarosa Polimeni, Didier Rocancourt, et al.

Genes Dev. 2003, 17:

Access the most recent version at doi:10.1101/gad.281203

References This article cites 71 articles, 30 of which can be accessed free at:

http://genesdev.cshlp.org/content/17/23/2950.full.html\#ref-list-1

License

Email Alerting

Receive free email alerts when new articles cite this article - sign up in the box at the top

Service

right corner of the article or click here.

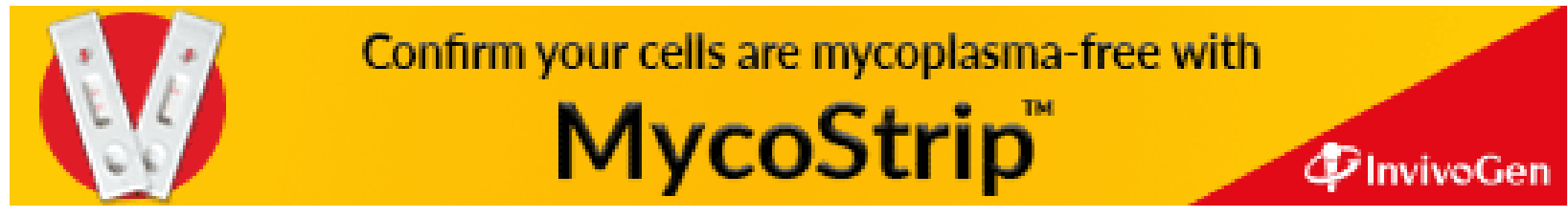

